\title{
QUEEN'S
UNIVERSITY
BELFAST
}

\section{Oxidative dehydrogenation of propane with N2O over Fe-ZSM-5 and Fe-SiO2: Influence of the iron species and acid sites}

Ates, A., Hardacre, C., \& Goguet, A. (2012). Oxidative dehydrogenation of propane with N2O over Fe-ZSM-5 and Fe-SiO2: Influence of the iron species and acid sites. Applied Catalysis A: General, 441, 30-41. https://doi.org/10.1016/j.apcata.2012.06.038

Published in:

Applied Catalysis A: General

Document Version:

Peer reviewed version

Queen's University Belfast - Research Portal:

Link to publication record in Queen's University Belfast Research Portal

\section{Publisher rights}

This is the author's version of a work that was accepted for publication in APPLIED CATALYSIS A-GENERAL . Changes resulting from the publishing process, such as peer review, editing, corrections, structural formatting, and other quality control mechanisms may not be reflected in this document. Changes may have been made to this work since it was submitted for publication. A definitive version was subsequently published in APPLIED CATALYSIS A-GENERAL , VOL 441, 10/2012

\section{General rights}

Copyright for the publications made accessible via the Queen's University Belfast Research Portal is retained by the author(s) and / or other copyright owners and it is a condition of accessing these publications that users recognise and abide by the legal requirements associated with these rights.

Take down policy

The Research Portal is Queen's institutional repository that provides access to Queen's research output. Every effort has been made to ensure that content in the Research Portal does not infringe any person's rights, or applicable UK laws. If you discover content in the Research Portal that you believe breaches copyright or violates any law, please contact openaccess@qub.ac.uk. 


\section{Accepted Manuscript}

Title: Oxidative Dehydrogenation of Propane with $\mathrm{N}_{2} \mathrm{O}$ overFe-ZSM-5 and $\mathrm{Fe}-\mathrm{SiO}_{2}$ : Influence of the iron species and acid sites

Authors: Ayten Ates, Christopher Hardacre, Alexandre Goguet

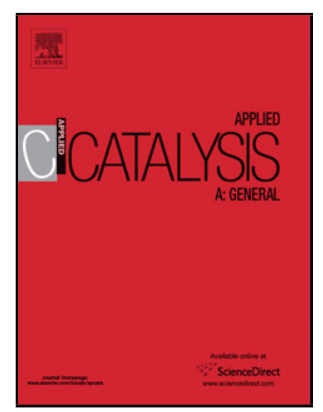

PII:

S0926-860X(12)00402-4

DOI: doi:10.1016/j.apcata.2012.06.038

Reference: APCATA 13752

To appear in: $\quad$ Applied Catalysis A: General

Received date: $\quad 20-2-2012$

Revised date: 22-6-2012

Accepted date: $\quad$ 24-6-2012

Please cite this article as: A. Ates, C. Hardacre, A. Goguet, Oxidative Dehydrogenation of Propane with $\mathrm{N}_{2} \mathrm{O}$ overFe-ZSM-5 and $\mathrm{Fe}_{-} \mathrm{SiO}_{2}$ : Influence of the iron species and acid sites, Applied Catalysis A, General (2010), doi:10.1016/j.apcata.2012.06.038

This is a PDF file of an unedited manuscript that has been accepted for publication. As a service to our customers we are providing this early version of the manuscript. The manuscript will undergo copyediting, typesetting, and review of the resulting proof before it is published in its final form. Please note that during the production process errors may be discovered which could affect the content, and all legal disclaimers that apply to the journal pertain. 
Graphical abstract

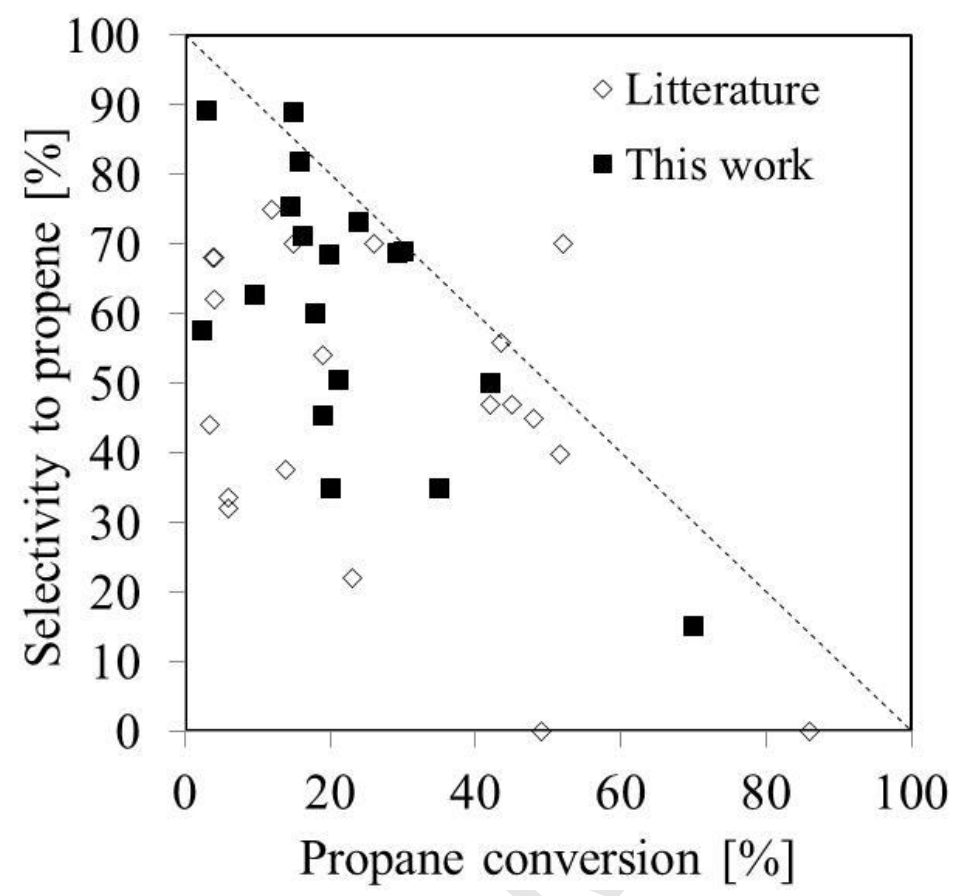




\section{Highlights}

Fe-ZSM-5 zeolites prepared with solid-state show high stability for ODHP.

The acidity degree of Fe-ZSM-5 is important for high propene selectivity.

The acidity of Fe-ZSM-5 can be controlled by the treatment conditions and Si/Al ratio.

Highly selective propane dehydrogenation to propene over $\mathrm{Fe}-\mathrm{SiO}_{2}$ is obtained. 


\section{Oxidative Dehydrogenation of Propane with $\mathrm{N}_{2} \mathrm{O}$ over}

\section{Fe-ZSM-5 and $\mathrm{Fe}-\mathrm{SiO}_{2}$ : Influence of the iron species and acid}

\section{sites}

Ayten Ates ${ }^{* a}$, Christopher Hardacre ${ }^{\mathrm{b}}$ and Alexandre Goguet ${ }^{\mathrm{b}}$

${ }^{a}$ Cumhuriyet University, Engineering Faculty, Department of Chemical Engineering, 58140 Sivas, Turkey. E-mail: ates@ cumhuriyet.edu.tr; Tel: +903462191010/2248; Fax:+903462191179

${ }^{\mathrm{b}}$ School of Chemistry and Chemical Engineering, Queen's University Belfast, Belfast BT9 5AG, Northern Ireland. E- mail: c.hardacre@qub.ac.uk., Tel: + 442890 974592; Fax: + 442890 974687; E-mail: a.goguet@qub.ac.uk, Tel: + 44 (0) 289097 4882, Fax: + 44 (0) 2890974687.

*Corresponding author current address: Department of Chemical Engineering, Massachusetts Institute of Technology, Cambridge, Massachusetts, US, 02139. 'a-mail: aates@mit.edu. 


\begin{abstract}
A series of iron containing zeolites with varying Si/Al ratios (11.5 to 140) and low iron content ( 0.9 wt. $\% \mathrm{Fe})$ have been synthesised by solid-state ion exchange with commercially available zeolites and tested, for the first time, in the oxidative dehydrogenation of propane (ODHP) with $\mathrm{N}_{2} \mathrm{O}$. The samples were characterised by XRD, $\mathrm{N}_{2}$-Adsorption, $\mathrm{NH}_{3}$-TPD and DR-UV-vis spectroscopies. The acidity of the Fe-ZSM-5 can be controlled by high temperature and steam treatments and $\mathrm{Si} / \mathrm{Al}$ ratio. The selectivity and yield of propene were found to be the highest over Fe-ZSM-5 with low Al contents and reduced acidity. The initial propene yield over Fe-ZSM-5 was significantly higher than that of $\mathrm{Fe}-\mathrm{SiO}_{2}$ since the presence of weak and/or medium acid sites together with oligonuclear iron species and iron oxides on the ZSM-5 are found to enhance the $\mathrm{N}_{2} \mathrm{O}$ activation. The coking of Fe-ZSM-5 catalysts could also be controlled by reduction of the surface acidity of ZSM- 5 and by the use of $\mathrm{O}_{2}$ in addition to $\mathrm{N}_{2} \mathrm{O}$ as the oxidant. Fe-ZSM-5 zeolites prepared with solid-state method have been shown to have comparable activity and better stability towards coking compared with Fe-ZSM-5 zeolites prepared by liquid ion exchange and hydrothermal synthesis methods.
\end{abstract}

Keywords: Fe-ZSM-5; Dehydrogenation of propane; propene; nitrous oxide; $\mathrm{Fe}_{-} \mathrm{SiO}_{2}$ 


\section{Introduction}

ZSM-5 zeolites with low iron contents have shown remarkable activity and selectivity in the oxidative dehydrogenation $(\mathrm{ODH})$ of propane with $\mathrm{N}_{2} \mathrm{O}$ [1-10] as well as in the hydroxylation of benzene [11-15] and other hydrocarbons [11, 16, 17]. The activity and selectivity in ODH of propane (ODHP) can be related to the structure of the ZSM-5, the type of oxidant used, the speciation of the iron and the pre-treatment of the catalysts. For example, it is clear that the acid-base properties of the ZSM-5 are important parameters in the performance of these types of catalysts. Nowinska et al. studied the influence of the acid site concentration on the selectivity and conversion of propane and ethane using $\mathrm{N}_{2} \mathrm{O}$ as the oxidant over Fe-ZSM-5 prepared by liquid phase ion exchange $[9,10,17]$. A decrease in Brønsted acid sites via high temperature treatment, sodium doping and hydrothermal treatment resulted in an increase in the propene selectivity, a slight change in the distribution of the cracking products as well as a decrease in the alkane conversion. In the presence of strong acid sites, both dehydrogenation and cracking reactions were reported to occur simultaneously whereas over medium/weak acid sites, the process was found to occur via consecutive reactions. Teixeira-Neto et al. and Bandiera et al. reported that, while the $\mathrm{C}-\mathrm{H}$ bond of propane is primarily activated on weak and medium acid sites and results in the production of olefins, $\mathrm{C}-\mathrm{C}$ bonds are primarily activated on strong acid sites and lead to the production of cracking products $[18,19]$. In order to reduce the concentration of strong acid sites, $\mathrm{Xu}$ et al. investigated the performance of zeolite based catalysts with a range of $\mathrm{Si} / \mathrm{Al}$ ratios for the dehydrogenation of propane [20]. They found that the activity in propane dehydrogenation decreased with increasing $\mathrm{Si} / \mathrm{Al}$ ratio while the opposite trend was observed regarding the catalyst stability. The enhanced stability with increasing $\mathrm{Si} / \mathrm{Al}$ ratio was linked to the reduced acidity of the catalysts, leading to the 
suppression of side reactions such as cracking and oligomerization. In contrast, PerezRamirez and Gallardo- Llamas reported that the initial propene yield over Fe-ZSM-5 and Fe-BEA prepared by hydrothermal synthesis was not affected by the catalyst acidity, the distribution of extraframework iron species or the zeolite structure [6]. They also reported that Fe-AlMFI and Fe-GaMFI had significantly higher stability in comparison to FeGeMFI and Fe-MFI with the former having 2- 3 times higher acid site density [7]. The differences observed between the acidity and ODHP performance of Fe-ZSM-5 zeolites prepared by hydrothermal synthesis or liquid ion exchange may be due to the types of iron species formed in each case and the nature of the pre-treatments used, as discussed below.

Fe-ZSM-5 prepared by methods leading to extra-framework iron led to catalysts having higher activity for $\mathrm{N}_{2} \mathrm{O}$ decomposition and higher initial activity for $\mathrm{ODH}$ of propane with $\mathrm{N}_{2} \mathrm{O}$ compared with other methods of preparation. These materials also showed lower resistance to deactivation. The high initial activity may be due to the presence of isolated and oligonuclear iron species in the extra-framework iron catalysts [21-24]. It has been proposed that the low stability could be improved by increasing the acidity [7] in contrast to ion exchange methods. Catalysts prepared by the solid-state iron exchange method, as studied in detail by Lobree et al. [25] have different active iron species such as large oxide clusters and small oxygen containing nanoclusters such as $\mathrm{Fe}_{4} \mathrm{O}_{4}$ and $\mathrm{Fe}_{3} \mathrm{O}_{4}$ [25-28] as well as isolated iron species. They reported that $\mathrm{Fe}^{3+}$ cations are exchanged with protons at the Brønsted acid sites on a one-to-one basis for an Fe/Al ratio of 0.56 and formed dispersed cations such as $\mathrm{Fe}(\mathrm{OH})^{2+}, \mathrm{Fe}(\mathrm{OH})^{+}$and $\mathrm{FeO}^{+}$. Additionally, Abu-Zied et al. reported that the solid- state ion exchange method has various advantages compared with other methods, such as the control of the metal loading, the possibility of exchanging multivalent cations 
into the zeolite, the reproducibility, the control of crystallite size and the generation of different active sites [29].

The pre-treatment conditions have also been reported to have a significant effect on the activity and selectivity for the ODH of propane with $\mathrm{N}_{2} \mathrm{O}$. These conditions have included high temperature calcination and/or steaming $[3,4,9,10,21-23,30]$. The high temperature treatment and steaming have been reported to increase the amount of extra-framework iron species in Fe-ZSM-5 prepared by hydrothermal method. It has also been reported that the high temperature treatments increased the activity for $\mathrm{N}_{2} \mathrm{O}$ decomposition and ODH of propane with $\mathrm{N}_{2} \mathrm{O}$ of Fe-ZSM-5 catalysts prepared by ion exchange [4, 30, 31].

The type and concentration of oxidants have also been reported to affect the activity and selectivity of Fe-ZSM-5. Monoatomic oxygen species $\left(\mathrm{O}^{2-}, \mathrm{O} \alpha, \mathrm{O}^{-}\right)$are formed upon $\mathrm{N}_{2} \mathrm{O}$ activation, while polyatomic oxygen species $\left(\left(\mathrm{O}_{2}\right)_{\mathrm{s}},\left(\mathrm{O}_{2}{ }^{-}\right)_{\mathrm{s}},\left(\mathrm{O}_{2}{ }^{2-}\right)_{\mathrm{s}}\right)$ as well as monoatomic species are formed from $\mathrm{O}_{2}$ activation [32]. The $\mathrm{O}^{-}$and/or monoatomic oxygen have been reported to be responsible for the $\mathrm{ODH}$ of propane over the iron species [4-6]. Nowinska et al. proposed that, upon $\mathrm{N}_{2} \mathrm{O}$ decomposition, the surface oxygen formed is responsible for the production of oxygenates such as acetaldehyde [4]. Perez-Ramirez et al. suggested that the monoatomic oxygen species are involved in the conversion of propane to propene [5, $6]$.

While Fe-ZSM-5 catalysts prepared by hydrothermal or ion exchange methods have been studied extensively for the $\mathrm{ODH}$ with $\mathrm{N}_{2} \mathrm{O}$ reaction, similar catalysts prepared by solidstate exchange have only been the subject of a limited number of investigations. To the best of our knowledge, alkane dehydrogenation reactions have only been reported using Zn, Mo and Co modified ZSM-5 catalysts prepared by solid state methods [33]. In this case, propane aromatization was reported and demonstrated that highly active catalysts 
could be formed via solid-state exchange. The present study compares, for the first time, a series of iron containing zeolites with varying $\mathrm{Si} / \mathrm{Al}$ ratios (11.5 to 140$)$ and low iron content ( $\sim 0.9$ wt. \% Fe) synthesised by solid-state ion exchange using commercially available zeolites for the dehydrogenation of propane following low temperature, high temperature or steam treatments. All catalysts were characterised by XRD, $\mathrm{N}_{2}$-Adsorption, $\mathrm{NH}_{3}$-TPD and DR-UV-vis spectroscopies in order to determine the impact of the various treatment and the $\mathrm{Si} / \mathrm{Al}$ ratio on the nature of the iron species present and the acidity of these catalysts and clarify their impact on the activity and selectivity for ODHP.

\section{Experimental}

\subsection{Catalysts preparation}

A range of parent zeolites $\left(\mathrm{NH}_{4}-\mathrm{ZSM}-5\right)$ with varying $\mathrm{Si} / \mathrm{Al}$ ratio were used in this study (Zeoliyst, Z: CBV2314, Si/Al=11.5; CBV3024E, Si/Al=15.0; CBV5524G, Si/Al=25.0; CBV8014, Si/Al=40.0; CBV28014, Si/Al=140; Süd-Chemie, SM27, Si/Al=12.5). A series of $\mathrm{Fe} / \mathrm{SiO}_{2}$ reference catalysts were also prepared. The silica support was obtained from Merck (medium pore size: $60^{\circ} \mathrm{A}$, particle size: $0.063-0.200 \mathrm{~mm}$ ). The pre-treatment of the silica and the deposition of the iron were undertaken using the procedures described by Ananieve and Reitzmann [34].

The iron was deposited on all the zeolites by a solid-state technique using $\mathrm{FeCl}_{2} \cdot 4 \mathrm{H}_{2} \mathrm{O}$ as the iron precursor at atmospheric pressure and $550{ }^{\circ} \mathrm{C}$, as described elsewhere [31]. The ammonia form of the zeolites was mixed with the iron precursor using a mortar and pestle under ambient conditions. All the samples had a nominal iron loading of $1.0 \mathrm{wt} . \%$. The physical mixture was heated up to $550{ }^{\circ} \mathrm{C}$ over $3 \mathrm{~h}$ and maintained at this temperature in air 
for $6 \mathrm{~h}$. Thereafter, the samples were cooled to room temperature, washed thoroughly with deionised water, dried at $120{ }^{\circ} \mathrm{C}$ and calcined at $600{ }^{\circ} \mathrm{C}$ in air for $1 \mathrm{~h}$. The samples are denoted as follows throughout the text: $\mathrm{SM} x \mathrm{Fey}$ or $\mathrm{Z} x \mathrm{Fe} y$, where $\mathrm{SM}$ and $\mathrm{Z}$ denote the zeolite supplier (Z: Zeoliyst and SM: Süd-Chemie) and $x$ and $y$ indicate the $\mathrm{SiO}_{2} / \mathrm{Al}_{2} \mathrm{O}_{3}$ ratio and wt.\% of $\mathrm{Fe}$, respectively. The $\mathrm{Fe}-\mathrm{SiO}_{2}$ catalysts were prepared by wet impregnation of the silica support with a solution of Fe(III) acetylacetonate (Aldrich) in toluene at ambient temperature and atmospheric pressure for $15 \mathrm{~h}$. The solvent was then evaporated and the sample was dried and calcined in air at $600{ }^{\circ} \mathrm{C}$ for $5 \mathrm{~h}$. Three $\mathrm{Fe}-\mathrm{SiO}_{2}$ catalysts were prepared by this method with iron contents of $0.1,0.67$ and 0.90 wt. $\%$. Before testing, the iron loaded silica was shaped by extrusion with Ludox (AS-40, Du Pont) and hydroxyl-ethylene-cellulose and the resulting extrudates were crushed and sieved to $250-500 \mu \mathrm{m}$ particles.

\subsection{Characterisation of the catalysts}

The chemical composition of the catalysts was measured using ICP. Powder X-ray diffraction (XRD) was performed on a PANalytical X'Pert Pro X-ray diffractrometer using $\mathrm{Cu} \mathrm{K \alpha}$ radiation, with a $0.017^{\circ}$ step size at room temperature and the spectra were recorded over a $2 \theta$ range of $5-65^{\circ}$. Diffuse reflectance ultraviolet-visible spectroscopy (DR-UV-vis) measurements were performed at $30{ }^{\circ} \mathrm{C}$ and $400{ }^{\circ} \mathrm{C}$ after each treatment, using a Lambda 650S UV-vis spectrophotometer equipped with a Harrick high temperature reaction chamber and an integrating sphere detector. The parent zeolites and the silica support were used as reference. The BET surface areas of the samples were measured with an Autosorb 1C, Quantachrome gas sorption apparatus. 
Low temperature (LT), steam (ST) and high temperature (HT) treatments were performed at $500{ }^{\circ} \mathrm{C}$ in $\mathrm{He}(\mathrm{LT})$ for $2 \mathrm{~h}$, at $600{ }^{\circ} \mathrm{C}$ in $30 \% \mathrm{H}_{2} \mathrm{O}$ in $\mathrm{He}$ for $5 \mathrm{~h}$ (ST) and at $900{ }^{\circ} \mathrm{C}$ in $\mathrm{He}$ for $2 \mathrm{~h}(\mathrm{HT})$, respectively. Additionally, to explore the combined effect of treatments the samples were treated at HT for $2 \mathrm{~h}$ after the ST, and denoted as STHT.

Ammonia temperature-programmed desorption (TPD-NH$)$ was carried out in an Autochem II- 2920, Micromeritics. Typically, the samples were saturated with a flow of $15 \% \mathrm{NH}_{3}$ in $\mathrm{He}$ at $50{ }^{\circ} \mathrm{C}$. Subsequently, $\mathrm{NH}_{3}$ was desorbed in a He flow of $25 \mathrm{~cm}^{3} \mathrm{~min}^{-1}$ using a ramp rate of $10{ }^{\circ} \mathrm{C} \min ^{-1}$ up to a temperature of $700{ }^{\circ} \mathrm{C}$.

Thermogravimetric (TG) measurements were performed in a TGA-50 apparatus (Shimadzu). These ex-situ measurements allowed analyzing the amount of coke deposited on the samples during long term ODH of propane tests (415 min). Typically, these measurements were performed in a flow of air with a maximum of $10 \mathrm{mg}$ of samples and a temperature ramp rate of $10{ }^{\circ} \mathrm{C} \min ^{-1}$ from ambient temperature to $900{ }^{\circ} \mathrm{C}$.

\subsection{Catalytic tests}

The ODHP with $\mathrm{N}_{2} \mathrm{O}$ was carried out in a fixed bed reactor (i.d.=20 mm) at atmospheric pressure. The amount of catalyst used was $0.5 \mathrm{~g}$. The feed composition was $5 \% \mathrm{~N}_{2} \mathrm{O}$ and $5 \% \mathrm{C}_{3} \mathrm{H}_{8}$ in $\mathrm{He}$ with a total flow rate of $200 \mathrm{~cm}^{3} \mathrm{~min}^{-1}$ unless otherwise stated. All experiments were performed at 450 or $500{ }^{\circ} \mathrm{C}$. Before the ODHP activity tests, the samples were pre-treated using the LT, ST, HT or STHT conditions. For the long term ODHP activity tests and the subsequent evaluation of the amount of coke deposited, the experiments were conducted for $415 \mathrm{~min}$ and the products analysed every $20 \mathrm{~min}$. For all ODHP tests, the reactants and products were analysed by on-line gas chromatography (Agilent 2920) equipped with both a TCD and a FID detector. Plot Q and Molsieve 3A 
columns were used to separate $\mathrm{N}_{2}, \mathrm{O}_{2}$ and $\mathrm{N}_{2} \mathrm{O}$ and an $\mathrm{Al} / \mathrm{S}$ column was used to separate the organic compounds such as methane, ethane, propane and propene. The conversion $(X)$, yield $(Y)$ and selectivity $(S)$ were calculated using the following equations:

$X_{\mathrm{C} 3 \mathrm{H} 8}=\left(C^{\mathrm{O}}{ }_{\mathrm{C} 3 \mathrm{H} 8}-C_{\mathrm{C} 3 \mathrm{H} 8}\right) / C^{\mathrm{O}}{ }_{\mathrm{C} 3 \mathrm{H} 8}$

$X_{\mathrm{N} 2 \mathrm{O}}=\left(C^{\mathrm{O}}{ }_{\mathrm{N} 2 \mathrm{O}}-C_{\mathrm{N} 2 \mathrm{O}}\right) / C^{\mathrm{O}}{ }_{\mathrm{N} 2 \mathrm{O}}$

$Y_{\mathrm{C} 3 \mathrm{H} 6}=C_{\mathrm{C} 3 \mathrm{H} 6} / C^{\mathrm{o}}{ }_{\mathrm{C} 3 \mathrm{H} 8}$

$S_{\mathrm{C} 3 \mathrm{H} 6}=Y_{\mathrm{C} 3 \mathrm{H} 6} / X_{\mathrm{C} 3 \mathrm{H} 8}$

where $C_{i}^{o}$ and $C_{i}$ refer to the input and output concentrations of species mol/L, respectively.

\section{Results}

\subsection{Characterisation of the catalysts}

\section{Chemical composition and $X$-ray diffraction}

Table 1 reports the chemical composition of the $\mathrm{Fe}-\mathrm{ZSM}-5$ and $\mathrm{Fe}-\mathrm{SiO}_{2}$ catalysts determined by ICP. Some differences from the nominal loadings were found. Similar differences have been reported previously $[29,30]$ and have been tentatively attributed to $\mathrm{HCl}$ formed in the washing step during preparation causing a loss of iron and/or aluminium. In the case of the $\mathrm{Fe}-\mathrm{SiO}_{2}$ catalysts, the measured iron contents were close to the theoretical amounts.

The XRD patterns for the Fe-ZSM-5 samples as a function of the various thermal treatments were measured (not shown). Neither LT nor HT treatments significantly affected the zeolite crystallinity. Conversely, following ST, a significant reduction in the 
intensity of the XRD peaks was observed which is consistent with de-alumination of the zeolite [12,14]. In all cases, for both zeolite and silica samples, little change in the XRD patterns were observed between the parent zeolite and the iron loaded sample.

\section{Nitrogen adsorption}

The textural properties of the samples after LT, HT and ST treatments were investigated by nitrogen adsorption. The isotherms obtained for all zeolite samples were of Type I as expected for microporous solids [35]. The specific surface area, pore volumes and average pore diameters for the fresh and treated samples are reported in Table 2. Almost all Fe-ZSM-5 samples treated at HT showed a decrease in BET area, pore volume and average diameter of the micropores (Table 2) which is likely to be due to the aggregation of iron species in the micropores. After LT and HT treatment, the hysteresis between adsorption and desorption for $p / p^{o}>0.5$ became much less significant indicating the very small contribution of the mesoporosity to the overall porosity of the treated samples. After the ST treatment, the $\mathrm{N}_{2}$ uptake for the samples did not change significantly. A hysteresis between adsorption and desorption isotherms of $\mathrm{N}_{2}$ in $\mathrm{Fe}-\mathrm{SiO}_{2}$ (not shown) indicated the presence of mesopores, as expected for silica. Overall, the deposition of the iron resulted in only small modifications of the BET isotherm profiles.

\section{$D R-U V$-vis spectroscopy}

Figure 1 shows the DR-UV-vis spectra of the Fe-ZSM-5 samples after the LT, HT and ST treatments. For similar catalysts reported previously, bands at $230 \mathrm{~nm}, 250 \mathrm{~nm}, 270 \mathrm{~nm}$, $338 \mathrm{~nm}$ and above $400 \mathrm{~nm}$ have been observed [13, 22, 36-39]. Perez-Ramirez et al. 
identified three spectral regions corresponding to bands at wavelengths $<300 \mathrm{~nm}$ associated with isolated $\mathrm{Fe}^{3+}$ ions, bands between 300 and $400 \mathrm{~nm}$ ascribed to small oligonuclear $\mathrm{Fe}_{x}^{3+} \mathrm{O}_{y}$ clusters and bands above $400 \mathrm{~nm}$ corresponding to $\mathrm{Fe}_{2} \mathrm{O}_{3}$ nanoparticles on the external surface of the zeolite [22]. Similar assignments have been reported by Centi et al. [12-14] and Berlier et al. [37]. For the Fe-ZSM-5 samples studied, herein, treated at LT (Figure 1a) a feature at $\sim 225 \mathrm{~nm}$ was observed for all samples. This is consistent with the presence of isolated $\mathrm{Fe}^{3+}$ sites in the tetrahedral coordination. In addition, all the samples displayed broad peaks around $270 \mathrm{~nm}$ indicating the presence of isolated iron species in square-pyramidal and distorted octahedral coordination [40]. For samples with low Si/Al ratios (11.5- 25), features were also observed between 300 and 400 nm (a peak for Z30Fe1.0 and shoulders for Z23Fe1.0 and Z50Fe1.0). This indicated the presence of small oligonuclear $\mathrm{Fe}_{x}{ }^{3+} \mathrm{O}_{y}$ clusters. Additionally, all samples displayed broad bands above $450 \mathrm{~nm}$ due to the presence of large $\mathrm{Fe}_{2} \mathrm{O}_{3}$ particles. Figures $1 \mathrm{~b}$ and $\mathrm{c}$ show the DR-UV-vis spectra for the samples after ST and HT treatments, respectively. Both treatments led to a decrease in the intensity of the bands located below $300 \mathrm{~nm}$ and the appearance of broad bands above $400 \mathrm{~nm}$ due to the sintering of isolated iron species into larger iron oxide species [41]. The DR-UV-vis spectra for the $\mathrm{Fe}_{-} \mathrm{SiO}_{2}$ catalysts are reported in Figure 1d. At low iron loadings, a single band around $270 \mathrm{~nm}$ is observed. As the loading of iron is increased an additional band at $300 \mathrm{~nm}$ is observed. As expected the increased iron loading leads to the formation of small oligonuclear clusters $\left(\mathrm{Fe}_{x}{ }^{3+} \mathrm{O}_{y}\right)$ in addition to the isolated iron species which are present at the lower loadings. 
$\mathrm{NH}_{3}-\mathrm{TPD}$

Figure 2 shows the $\mathrm{NH}_{3}$-TPD profiles obtained for the parent zeolites after LT and HT treatments. Three desorption peaks were observed at 100, 180 and $400{ }^{\circ} \mathrm{C}$. The peaks at $100{ }^{\circ} \mathrm{C}$ and $400{ }^{\circ} \mathrm{C}$ denote physically and strongly adsorbed ammonia on Brønsted and/or Lewis acid sites, respectively [25, 42-44]. The attribution of the peak at $200{ }^{\circ} \mathrm{C}$ is more complex. This peak may be due to ammonia weakly adsorbed on Brønsted/ Lewis acid sites [25, 42], ammonia associated with $\mathrm{Na}^{+}$[44] or extra-framework Al [42].

For the LT treatment, irrespective of the $\mathrm{Si} / \mathrm{Al}$ ratio, three desorption peaks were observed for all the parent zeolites with their intensity decreasing with increasing Si/Al ratio. After the HT treatment a strong decrease of the peak at $\sim 400{ }^{\circ} \mathrm{C}$ was observed for all zeolites which is consistent with a loss of Brønsted acid sites [10]. It is worth noting that the loss of acid sites has been thought to be due to partial dealumination [45]; however, from the XRD (not shown) and BET (Table 2) data little change following HT treatment is observed

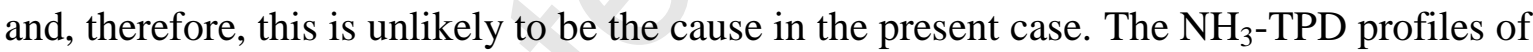
the parent and iron exchanged zeolites after LT treatment (Figure 3) showed that the peak observed at $\sim 400{ }^{\circ} \mathrm{C}$ with the parent zeolites significantly decreases on iron deposition for samples with a $\mathrm{Si} / \mathrm{Al}$ ratio of 50 or below. This is likely to be due to the exchange of surface protons by iron cations [25]. At higher $\mathrm{Si} / \mathrm{Al}$ ratios, the intensity of this peak is either unchanged or smaller, as seen in Figure 3, due to the formation of iron oxides at the lower alumina content. Moreover, at the highest $\mathrm{Si} / \mathrm{Al}$ ratio (Z280), the peak broadens and behaves similarly to that observed for the pure silica based catalysts reported in Figure 5 .

The $\mathrm{NH}_{3}$-TPD profiles of the different Fe-ZSM-5 samples after LT, ST and HT treatments are similar to those of the parent zeolites (Figure 4). In each case, the peak intensity 
decreased following the HT and ST treatments, which is indicative of a significant reduction of the acidity of the samples. The largest change was observed following ST which is consistent with the fact that such treatments result not only in the removal of Brønsted acid sites but also dealuminate the samples. This is consistent with other studies of similar materials and treatments $[12,14,41]$.

The $\mathrm{NH}_{3}$-TPD profiles of the $\mathrm{Fe}-\mathrm{SiO}_{2}$ are provided in Figure 5 and show that the amount of physically adsorbed ammonia increased with increasing iron content while the amount of ammonia desorbed for temperature above $600{ }^{\circ} \mathrm{C}$ follow the opposite trend. This is thought to be due to hydroxylation of the silica at temperatures higher than $600{ }^{\circ} \mathrm{C}$, as reported by Katranas et al. [46], which decreases with increasing iron content.

\subsection{Activity results of the catalysts}

\section{Oxidative dehydrogenation of propane with $\mathrm{N}_{2} \mathrm{O}$ over Fe-ZSM-5}

Figure 6 reports the ODHP performance of all Fe-ZSM- 5 catalysts at $450{ }^{\circ} \mathrm{C}$ after the LT treatment. The highest initial propane conversion, $40 \%$, was observed over the Z23Fe1.0 sample, but both the yield and selectivity for propene were low. The highest initial yield, $10 \%$, was obtained over the Z280Fe1.0 sample; however, the conversion and yield decreased with time on stream for samples with high $\mathrm{Si} / \mathrm{Al}$ ratios. This is not due to coking of the surface with little carbon deposition found as shown in Table 3 and the propene selectivity remained high. It is interesting to note that the highest deactivation rate was also observed in the $\mathrm{N}_{2} \mathrm{O}$ conversion. Considering that the $\mathrm{N}_{2} \mathrm{O}$ conversions decreased with time whilst the selectivity to propene increased and the propene yield was reasonably constant, it is likely that the deactivation observed is mainly due to the deactivation of the 
sites available for the direct decomposition of $\mathrm{N}_{2} \mathrm{O}$. This leads to a reduction in the unwanted combustion reactions, for example, and hence the increase in selectivity observed. For the samples with low $\mathrm{Si} / \mathrm{Al}$ ratios, methane, ethane, ethylene, butane and carbon dioxide were observed in addition to propene. In all cases the predominant byproducts were carbon dioxide and methane with the highest concentrations found for $\mathrm{Z} 23 \mathrm{Fe} 1.0$ in the range of $24-30 \%$ for $\mathrm{CO}_{2}$ and 3-7\% $\mathrm{CH}_{4}$. With time on stream, in contrast with the conversion of propane, the yield of $\mathrm{CO}_{2}$ increased. This is likely due to the conversion of propene or the other by-products such as methane, ethane, ethylene and butane to $\mathrm{CO}_{2}$ since their concentration decreased with time on stream. These by-products were also observed for the highest $\mathrm{Si} / \mathrm{Al}$ ratios (i.e. Z80Fe1.0 and Z280Fe1.0), but their concentrations were considerably lower in this case, which is consistent with the results previously reported for other Fe-ZSM-5 catalysts [9, 17].

Direct decomposition of $\mathrm{N}_{2} \mathrm{O}$ was performed over Fe-ZSM-5 zeolites treated at LT, ST and HT (not shown here) and decomposition activity changed in the order $\mathrm{HT}>\mathrm{ST}>\mathrm{L}$ T for all $\mathrm{Si} / \mathrm{Al}$ ratios. Similar experiments were repeated for Z80Fe1.0 and the highest yield of propene was observed over $\mathrm{Z} 80 \mathrm{Fe} 1.0$ treated at $\mathrm{HT}$ and the highest conversions of $\mathrm{N}_{2} \mathrm{O}$ and $\mathrm{C}_{3} \mathrm{H}_{8}$ were obtained over Fe80Fe1.0 treated at STHT. Therefore, the STHT pretreatment was subsequently systamatically applied to the samples evaulated for the ODH of propane.

Figure 7 reports the ODHP activities after consecutive ST and HT treatments. These led to an increase in both the conversions and selectivities of propane to propene compared with the LT treatment. The highest propane conversion was obtained for $\mathrm{Z} 80 \mathrm{Fe} 1.0$ whilst the highest $\mathrm{N}_{2} \mathrm{O}$ conversion was observed with $\mathrm{Z} 50 \mathrm{Fe} 1.0$. The highest selectivity for propene was obtained for Z280Fe1.0 and the highest yield was obtained with Z23Fe1.0, 
respectively. On the basis of these results, no direct correlation between ODHP performances and the Si/Al ratio of the sample could be drawn. It should be noted, however, that the trend obtained in Figure 7 with such treatment is opposite to that obtained with the samples treated at LT and that the stability of the samples toward coking is increased as seen in Figure 7. This may be due to the formation of small oligonuclear $\mathrm{Fe}_{x}^{3+} \mathrm{O}_{y}$ clusters and of large $\mathrm{Fe}_{2} \mathrm{O}_{3}$ particles following these treatments, as seen in the DRUV-vis spectra, which are produced as a result of surface defect formation and dealumination. This is consistent with a number of studies which have also shown that such changes in the catalysts increase the ODHP activity [41, 45, 47-49]. The increase in propene yield and selectivity is thought to be strongly dependent on the removal of Brønsted acid sites which are responsible for oligomerization and cracking reactions leading to coking. In addition, the increased stability towards coking can be the result of the decrease in micropore diameter. Perez-Ramirez and Gallardo-Llamas reported that coke precursors either cannot be trapped inside at the pores intersections or oxidised via molecular oxygen formed through recombination of atomic oxygen adsorbed from $\mathrm{N}_{2} \mathrm{O}$, and thereby diffuse easily due to their weak adsorption [6]. This is consistent with the BET results (Table 2) obtained for the catalysts studied, herein.

Based on the thermogravimetric results of the Fe-ZSM-5 samples used in ODHP for 415 min, reported in Table 3, the coke content of zeolites decreases as a function of the treatment applied in the order ST > HT > STHT, which is consistent with the activity results. The reason for the dependence of the coke accumulation on the treatment used can be summarized as follows: (i) decreasing of Brønsted acid sites; (ii) the conversion of inactive irons species to oligonuclear iron species and/or iron oxides and dealumination, 
increasing of the molecular oxygen formation which may lead to oxidation of coke; (iii) the elimination of the iron species which are responsible for coking.

\section{ODHP over $\mathrm{Fe}-\mathrm{SiO}_{2}$}

Figure 8 reports the ODHP activity results obtained with $\mathrm{Fe}-\mathrm{SiO}_{2}$ catalysts. Clearly, the activity increased with increasing iron content. Compared with the results obtained with the Fe-ZSM-5 samples (irrespective of the Fe loading and Si/Al ratio of the zeolite based catalysts) the ODHP activity over $\mathrm{Fe}-\mathrm{SiO}_{2}$ was found to be much lower. This difference is likely to be due to the type of the iron species present on the silica and the absence of acid sites. Based on DR-UV-vis results, isolated iron species and/or small oligonuclear iron clusters $\left(\mathrm{Fe}_{x}{ }^{3+} \mathrm{O}_{y}\right)$ exist on both $\mathrm{Fe}-\mathrm{ZSM} 5$ and $\mathrm{Fe}-\mathrm{SiO}_{2}$ samples. Considering that the nonquantitative aspect of the DR-UV-Vis data it is, therefore, difficult to draw an accurate relationship between the activity and relative proportion and nature of the iron species present. The very high propene selectivity (almost 100\%) during the ODH of propane over $\mathrm{Fe}-\mathrm{SiO}_{2}$ may be due to the absence of $\mathrm{Al}$; however, these results need to be noted with caution since they were obtained at low conversion, the selectivity is likely to decrease with increasing conversion. Keeping this aspect in mind, and assuming that the contribution of $\mathrm{Al}$ is real, one could be tempted to introduce aluminium into the silica matrix in order to increase the activity for ODHP of such catalysts. However, in this case the resulting increase in the concentration of acid sites, while likely to improve the ODH activity, will also enhance the cracking of propane. It is for this reason that Perez- Ramirez and Gallardo-Llamas [6] reduced the Brønsted and Lewis acid sites of the zeolites studied, therein, via steaming after introduction of $\mathrm{Al}$. 


\section{The influence of the oxidant on ODHP performance}

$\mathrm{N}_{2} \mathrm{O}$ for ODHP over Fe-ZSM-5 zeolites is a more selective but less active oxidant as compared with molecular oxygen [4]. Recently, Bulánek and Novoveská reported the three-fold higher yield of propene over $\mathrm{CoH}$-BEA zeolite by addition of nitrous oxide to oxygen [2]. This is explained by a synergetic effect of oxygen and nitrous oxide. Although this effect has not been fully explained it is likely to be due to the activation of $\mathrm{O}_{2}$ and $\mathrm{N}_{2} \mathrm{O}$ on different iron species. Therefore, in order to optimize the performance of the present catalysts, the impact of the composition of the feed in terms of the oxidant composition has been explored. Table 4 summarises the propane conversion and propene yield and selectivity for the zeolite (LT) and silica based iron catalysts at 450 and $500{ }^{\circ} \mathrm{C}$ using different feed mixtures in terms of $\mathrm{C}_{3} \mathrm{H}_{8} / \mathrm{N}_{2} \mathrm{O} / \mathrm{O}_{2}$. Comparing all the zeolite based catalysts using $5 \%$ propane $+5 \%$ nitrous oxide, the highest propene yield and propane conversion were observed over Z280Fe1.0. However, using 5\% propane $+5 \%$ oxygen, a decrease in both the yield and conversion was observed for both Z280Fe1.0 and Z80Fe1.0 with the activity over Z80Fe1.0 found to be slightly higher than that over Z280Fe1.0. Using a 1:1 mixture of $\mathrm{O}_{2}$ and $\mathrm{N}_{2} \mathrm{O}$ also resulted in a decrease in the conversion of propane as well as the yield of propene in comparison with pure $\mathrm{N}_{2} \mathrm{O}$ as the oxidant, albeit much smaller than when pure $\mathrm{O}_{2}$ was used. Significant increases in both yield and conversion were observed, however, on increasing the $\mathrm{N}_{2} \mathrm{O}$ concentration by a factor of two in the absence of $\mathrm{O}_{2}$ over Z80Fe1.0.

The results over the zeolite based catalysts are in contrast with those obtained over the silica based materials. In this case, the highest conversion of propane and yield of propene over $\mathrm{Fe}-\mathrm{SiO}_{2}$ were observed when a mixture of $\mathrm{N}_{2} \mathrm{O}$ and $\mathrm{O}_{2}$ was used, albeit still much smaller than virtually all the conditions used for the zeolite catalysts. 
The results show that $\mathrm{N}_{2} \mathrm{O}$ activation on Fe-ZSM-5 is possible while both $\mathrm{O}_{2}$ and $\mathrm{N}_{2} \mathrm{O}$ activation on $\mathrm{Fe}_{-} \mathrm{SiO}_{2}$ can be achieved. Previous studies showed that the $\mathrm{O}^{-}$and/ or monoatomic oxygen is responsible for the ODHP over the iron species [4-6]. According to the reports of Panov et al, the $\mathrm{O}^{-}$and/ or monoatomic oxygen can originate from both $\mathrm{O}_{2}$ and $\mathrm{N}_{2} \mathrm{O}$ [21]. The percentage of these oxygen species is high on iron containing zeolites using $\mathrm{N}_{2} \mathrm{O}$ as the oxidant. Whereas $\mathrm{O}_{2}$ and $\mathrm{N}_{2} \mathrm{O}$ can activate on the oligonuclear iron species and larger iron oxides formed in silica and/or zeolites, the presence of acid sites (weak and medium) along with these iron species can enhance $\mathrm{N}_{2} \mathrm{O}$ activation as seen in Fe-ZSM-5 with low alumina content and treated in HT and ST.

In relation to the catalyst performance, the highest propene yield was $20 \%$ over the $\mathrm{Z} 80 \mathrm{Fe} 1.0$ for $\mathrm{N}_{2} \mathrm{O}: \mathrm{C}_{3} \mathrm{H}_{8}: 2: 1$ and $7.0 \%$ over $\mathrm{FeSiO}_{2}-3$ for $\mathrm{N}_{2} \mathrm{O}: \mathrm{O}_{2}: \mathrm{C}_{3} \mathrm{H}_{8}=1: 1: 1$. Furthermore, the propene selectivity over $\mathrm{FeSiO}_{2}$ was high. This may be due to the absence of strong Brønsted acid sites for these catalysts.

\section{Discussion}

The performance of Fe-ZSM-5 zeolites on $\mathrm{ODH}$ of propane depends on the Si/Al ratio of zeolite, the iron species formed in the zeolite, their pre-treatment conditions and type and concentration of oxidant. Except for the case of Z280, increasing the Si/Al ratio led to a decrease in the initial conversion of propane and nitrous oxide and an increase in the initial selectivity of propane, but without a clear tend between the impact observed and the Si/Al value. Such behaviour may be associated with an increase in the cracking activity of different zeolites with increasing acidity (i.e Al content) as observed with the $\mathrm{NH}_{3}-\mathrm{TPD}$ results. With time on stream, a decrease in the conversion of propane and nitrous oxide is 
observed, which is most prominent at the lower $\mathrm{Si} / \mathrm{Al}$ ratios. Similar results were reported by Held et al. [17] for the dehydrogenation of ethane with $\mathrm{N}_{2} \mathrm{O}$. While high conversion of ethane and low selectivity of ethylene were observed for $\mathrm{Si} / \mathrm{Al}$ of 25 and 50, an opposite result was obtained when the Si/Al was 100 . The low selectivity for ethylene in case of the $\mathrm{Si} / \mathrm{Al}$ of 25 and 50 was related to the presence of high acidic centres (Brønsted or Lewis sites) determined by $\mathrm{NH}_{3}$-TPD.

Interestingly, while steam and high temperature treatments led to a significant increase in the ODH activity of propane of the iron containing zeolite catalysts explored in this study, it did not adversely affect their stability. Based on the $\mathrm{NH}_{3}-\mathrm{TPD}$ and DR-UV-vis results, these improvements with such treatments are likely to be the result of not only a decrease in Brønsted/Lewis acidy but also in the transformation of iron species introduced into the zeolites. Numerous studies have attempted to explain what happen during the treatment at high temperatures and/or steaming treatments for Fe-ZSM-5 zeolites prepared with different methods (hydrothermal method, ion exchange and CVD ) for ODH of propane and decomposition of $\mathrm{N}_{2} \mathrm{O}$ in literature and discussed by the impact of treatments by various groups. Based on the characterisation results from this study and previous results, it may be proposed that high temperature treatments lead to redispersion of iron oxide clusters $[30,50,51]$, the formation of small iron oxide clusters such as $-\mathrm{Fe}-\mathrm{O}-\mathrm{Al}$ like species and isolated $\mathrm{Fe}^{2+}$ species $[48,50,52-54]$, the creation of hydroxyl nests by dealumination $[12,14]$, the formation of mono and bi/oligonuclear iron [24], the migration of iron ions located on the outer surface into the pore system [10] and the conversion of $\mathrm{Fe}^{3+}$ to $\mathrm{Fe}^{2+}[55,56]$.

Clearly, the $\mathrm{NH}_{3}$-TPD results showed that the concentration of Brønsted and/or Lewis acid sites of the zeolite catalysts could be reduced by the introduction of iron, the increase of $\mathrm{Si} / \mathrm{Al}$ ratio and the high temperature and steam treatments. The relationship between iron 
introduction and acid sites was reported in our previous study of the decomposition of $\mathrm{N}_{2} \mathrm{O}$ over Fe-ZSM-5 zeolites containing varying iron contents and Si/Al ratios [57] which demonstrated that the formation of active iron species necessitates the presence of an optimal $\mathrm{Si} / \mathrm{Al}$ ratio. This ratio is not important for lower iron loaded catalysts $(\mathrm{Fe} \leq 3.30 \mathrm{wt}$ $\%$ ) because $\mathrm{Fe}^{3+}$ cations for an $\mathrm{Fe} / \mathrm{Al}$ ratio of 0.56 are exchanged with the protons of the Brønsted acid sites on a one-to-one basis and formed dispersed cations such as $\mathrm{Fe}(\mathrm{OH})^{2+}$ $\mathrm{Fe}(\mathrm{OH})^{+}$and $\mathrm{FeO}^{+}[25]$.

In case of zeolite catalysts prepared by solid-state exchange of iron and containing low $\mathrm{Si} / \mathrm{Al}$ ratio( $\mathrm{Si} / \mathrm{Al} \leq 50)$ a reduced $\mathrm{HT}$ peak as compared with the protonic form is observed in the $\mathrm{NH}_{3}$-TPD profile (Figure 3). The decrease of the HT peak area corresponds approximately to a compensation of negative charges in the zeolite on a 1:1 basis probably due to the incorporation of the cationic iron precursors. However, the total amount of $\mathrm{NH}_{3}$ desorbed from the Z80 and Z280 samples is not significantly affected by the presence of iron species. This was unexpected when assuming a compensation of negative charges by iron cations as in the case of lower $\mathrm{Si} / \mathrm{Al}$ ratios. Although $\mathrm{NH}_{3}-\mathrm{TPD}$ is known not to be highly quantitative, in the present case quantifying the influence of iron exchange on the number of Brønsted sites in zeolites, Lobree et al. have shown that results of $\mathrm{NH}_{3}$-TPD experiments correaltes well with the number of bridged hydroxyl groups determined by FTIR for a ZSM5 zeolite $(\mathrm{Si} / \mathrm{Al}=27)$ exchanged with different amounts of $\mathrm{FeCl}_{3}$ [25]. Both characterisation methods have shown that iron cations can replace up to approximately $60 \%$ of the Brønsted acid protons. In addition, an introduction of iron into lattice defects forming Brønsted sites is also possible, particularly for zeolites with higher $\mathrm{Si} / \mathrm{Al}$ ratio, as shown by El-Malki et al. using a variety of characterization techniques [58]. This means for the present study that the compensation of Brønsted acid protons by iron 
cations can only be detected in $\mathrm{NH}_{3}$-TPD when isolated cations are present, as for $\mathrm{Z} 23$, $\mathrm{Z} 30$ and $\mathrm{Z} 50$ with low iron contents. At higher $\mathrm{Si} / \mathrm{Al}$ ratios, the formation of bi- and oligonuclear iron oxo/ hydroxo-species are formed on the surface as well as isolated iron species.

High temperature and steam treatments led to a decrease the total concentration of acid sites and transformation of iron species as seen in Figures 1 and 4 . In particular, a significant decrease in the acid concentration was observed after steam treatment of the FeZSM-5, likely due to the fact that steam treatment also induces extensive dealumination of the zeolite and decrease the density of Brønsted acidic sites. This was supported by both XRD and $\mathrm{NH}_{3}$-TPD results presented, herein. A similar behaviour after steaming were observed by various groups $[41,48,59]$. Additionally, DR-UV-vis results showed that the steam treatment increases the concentration of oligonuclear iron species and highly dispersed iron oxide nanoparticles of 1-2 $\mathrm{nm}$ in the zeolites.

The decrease in acid sites seems to be linked to a change in the product distribution as well as the conversions of propane and nitrous oxide and selectivity to propene. For example, the selectivity of cracking products is decreased. As stated in the introduction, this can be explained by the fact that only medium and weak acidic sites are responsible for the $\mathrm{C}-\mathrm{H}$ bond activation, involved in oxidative dehydrogenation pathway [18, 19]. This is supported by the work of Held et al. who reported that the reduction of acid sites by means of high temperature treatment and sodium introduction, results in a clear decrease in selectivity to cracking products and $\mathrm{CO}_{2}$, while selectivity towards propene increased [10]. Additionally, Held et al. [9] and Bulanek et al. [3] showed that strong acidic sites gave rise to simultaneous formation of $\mathrm{ODH}$ and cracking of propane. According to literature data [60-62] the propene formed may undergo dimerization in the presence of medium and weak acidic centres and then can be further converted to shorter hydrocarbons through 
cracking. This behaviour may explain why, in addition to $\mathrm{CO}_{2}$, various hydrocarbons such as methane, ethylene, ethane and butane are observed as a by-products. Interestingly, the concentration of these by products is higher at the beginning of the reaction over Fe-ZSM5 zeolites with low $\mathrm{Si} / \mathrm{Al}$ ratio and treated at low temperatures. In such cases, methane and ethane should be mostly formed from cracking of propane. Ethylene could be formed the oxidative dehydrogenation of ethane $[10,17,62]$, while butane may be formed by oligomerization of ethylene on the Fe-ZSM-5 zeolites as reported by Amin and Anggoro [63]. $\mathrm{CO}_{2}$ can be formed from methane, ethylene, ethane, and butane as well as propane and propylene total combustion [10, 17, 62, 63].

Compared with the Fe-ZSM-5 catalysts, $\mathrm{Fe}-\mathrm{SiO}_{2}$ catalysts showed lower propane conversion and higher propene selectivity. As highlighted previously, a direct comparison is difficult since conversion was much lower than the zeolite based catalysts which is known to influence positively the selectivity figures. Keeping these aspect in mind several observation can be made, the activity differences may be due to the presence of $\mathrm{Al}$ in the zeolite based catalysts as well as different iron species formed in the different samples. In case of the different iron species, based on DR-UV-vis results, both samples contain small oligonuclear clusters $\left(\mathrm{Fe}_{x}{ }^{3+} \mathrm{O}_{y}\right)$ and isolated iron species as well as iron oxide nanoparticles of 1-2 $\mathrm{nm}$. Therefore, it is difficult to find a relationship between iron species and the activity forthe $\mathrm{ODH}$ of propane. However, the presence of $\mathrm{Al}$ on Fe-ZSM-5 (possibly in the form of $\mathrm{Fe}-\mathrm{O}-\mathrm{Al}$ ) can enhance the activation of propane and nitrous oxide as reported by Hensen et al. [52, 53].

The activity and selectivity of ODHP strongly depends on the nature of the oxidant used. Propane mainly converts to propene with $\mathrm{N}_{2} \mathrm{O}$ and $\mathrm{O}_{2}$ over Fe-ZSM-5 and Fe-SiO 2 . Moreover, the use of $\mathrm{O}_{2}$ as the oxidant reduced the coke content, as seen in Table 3, and, 
therefore, this may indicate that the polyatomic oxygen species formed from $\mathrm{O}_{2}$ oxidise the coke precursors. As reported by Perez-Ramirez and Gallarda-Llamas for ODHP $[6,7]$ and Pirutko et al. [64] for the direct oxidation of benzene to phenol (BTOP), the presence of Brønsted acidity in the zeolites activates iron species responsible for these reactions. As already stated $[18,19]$, the selectivity and yield of propene is high on the zeolites with lower Al content and with acidity reduced via HT and ST treatments, leading to weak and medium acid sites responsible for the activation of the $\mathrm{C}-\mathrm{H}$ bond of propane.

ODHP has been studied previously on Fe-ZSM-5 prepared using hydrothermal or ion exchange methods. The highest values for conversion of propane and selectivity and yield of propene were observed for Fe-ZSM-5 zeolites prepared with hydrothermal method and using $\mathrm{N}_{2} \mathrm{O}$ and $\mathrm{N}_{2} \mathrm{O}+\mathrm{O}_{2}$ as the oxidant $[3,6,7]$. However, a drawback of these methods is the rapid deactivation of the catalysts. Perez Ramirez and Galarda - Llamas were able to stabilise the activity through introduction of $\mathrm{Ga}$ and $\mathrm{Al}$ into the zeolite [7]. Although $\mathrm{Fe}$ ZSM-5 zeolites prepared with ion exchange by Nowinska et al. showed comparable propene yield (22\%) using Fe-ZSM-5 treated at $900{ }^{\circ} \mathrm{C}$ compared with the hydrothermally prepared catalysts, the selectivity to propene and the conversion of propane were lower than that obtain with hydrothermal methods [4]. Figure 9 reports the conversionselectivity plot of the best results obtained with our catalysts and those reported previously for Fe-ZSM-5 catalysts using similar conditions $[2-5,8,10]$. As expected, all the points (with only one exception) were located on the lower left hand size of the line linking the $100 \%$ conversion and $100 \%$ selectivity poles. Moreover, the general trend of the results obtained was that of a decreasing propene selectivity with increasing propane conversion, which is the most commonly obtained trend in case of alkanes partial oxidation. Comparing these results with those previously reported, the representative points are 
reasonably close to the " $100 \%$ conversion and $100 \%$ selectivity" separation line. It is, therefore, reasonable to conclude that the Fe-ZSM-5 zeolites prepared, herein, by the solidstate method have comparable performance with Fe-ZSM-5 zeolites prepared with hydrothermal method and, most interestingly, stability towards coking as seen in Figure 7.

\section{Conclusions}

The ODH of propane on Fe-ZSM-5 prepared by solid-state methods as well as using Fe$\mathrm{SiO}_{2}$ has been examined in detail, for the first time. In particular, the effect of low temperature, high temperature and steam treatments on materials prepared by this method have been examined. Importantly, Fe-ZSM-5 zeolites prepared with solid-state method have been shown to have comparable activity and better stability towards coking compared with Fe-ZSM-5 zeolites prepared by hydrothermal synthesis. In addition, the acidity of FeZSM-5 which is shown to be important towards the ODH performance of these catalysts can be controlled by high temperature and steam treatments and $\mathrm{Si} / \mathrm{Al}$ ratio. In order to obtain high selectivity towards propene, the presence of weak and medium acid sites is necessary which can be obtained by steam and high temperature treatments as well as changes in the $\mathrm{Si} / \mathrm{Al}$ ratio. The steam treatment was found to lead to dealumination of the zeolites and aggregation of the iron species. Based on DR-UV-vis data, the cationic iron species can be converted into oxidic iron species and oligonuclear iron species via the steam treatment leading to an increase in conversion of propane conversion. Similar results were also found after a high temperature treatment. 


\section{Acknowledgements}

The authors acknowledge financial support from the Scientific and Technological Research Council of Turkey (107M236) and the EU Transnational Project grant held in CenTACat at Queen's University, Belfast.

\section{References}

[1] R. Bulanek, K. Novoveska, B. Wichterlova, Appl. Catal. A 235( 2002) 181-191.

[2] R. Bulanek, K. Novoveska, Reac. Kint. Catal. Lett. 80 (2003) 337-343.

[3] R. Bulanek, B. Wichterlova, K. Novoveska, V. Kreibich Appl. Catal. A 264 (2004) 1322.

[4] K. Nowinska, A. Waclaw A. Izbinska, Appl. Catal. A 243 (2003) 225-236.

[5] E. V. Kondratenko, J. Perez- Ramirez, Appl. Catal. A 267 (2004) 181-189.

[6] J. Perez-Ramirez, A. Gallardo-Llamas, J. Catal. 223 (2004) 382-388.

[7] J. Perez-Ramirez, A. Gallardo-Llamas, J. Phys. Chem. B 109 (2005) 20529-20538

[8] A. Gallardo- Llamas, C. Mirodatos, J. Perez- Ramirez, Ind . Eng. Chem. Res. 44 (2005) 455-462.

[9] A. Held, J. Kowalska, A. Tuchorska, K. Nowinska, Stud. Surf. Sci. Catal. 170 (2007) $1267-1274$

[10] J. Kowalska-Kus, A. Held, K. Nowinska, Catal. Lett. 136 (2010) 199-208.

[11] V. I. Sobolev, K. A. Dubkov, O. V. Panna, G. I. Panov, Catal. Today 24 (1995) 251252.

[12] G. Centi, C. Genovese, G. Giordano, A. Katovic, S. Perathoner, Catal. Today 91/92 (2004) 17-26. 
[13] G. Centi, S. Perathoner, F. Pino, R. Arrigo, G. Giordano, A. Katovic, V. Pedulà, Catal. Today 110 (2005) 211-220.

[14] G. Centi, S. Perathoner, R. Arrigo, G. Giordano, A. Katovic, V. Pedula, Appl. Catal. A 307 (2006) 30-41.

[15] T. Tatlier, L. Kiwi-Minsker, Catal. Commun. 6 (2005) 731-736.

[16] M. A. Rodkin, V.I. Sobolev, K. A. Dubkov, N. H. Watkins, G. I. Panov, Stud. Surf. Sci. Catal. 130 (2000) 875-880.

[17] A. Held, J. Kowalska, K. Nowinska, Appl. Catal. B 64 (2006) 201-208.

[18] J. Bandiera, M. Dufaux, Y. B. Taarit, Appl. Catal. B 148 (1997) 283-300.

[19] A. A. Teixeira- Neto, L. Marchese, G. Landi, L. Lisi, H. O. Pastore, Catal. Today 133-135 1(2008) 1-6.

[20] B. Xu, T. Li, B. Zheng, W. Hua, Y. Yue, Z. Gao, Catal. Lett. 119 (2007) 283-288.

[21] J. Perez-Ramirez, E. V. Kondratenko, Chemm. Commun. (2003) 2152-2153.

[22]J. Perez-Ramirez, M. S. Kumar, A. Brückner, J. Catal. 223 (2004) 13-27.

[23] J. Perez-Ramirez, J. G. Groen, A. Brückner, M. S. Kumar, U. Bentrup, M. N. Debbagh, L. A. Villaescusa, J. Catal. 332 (2005) 318-334.

[24] I. Yuranov, D. A. Bulushev, A. Renken, L. Kiwi-Minsker, J. Catal. 227 (2004) 138147.

[25] L. J. Lobree, I. C. Hwang, J. A. Reimer, A.T. Bell, J. Catal. 186 (1999) 242-253.

[26] R. Joyner, M. Stockenhuber, J. Phys. Chem. B 103 (1999) 5963-5976

[27] E. M. El-Malki, R. A. Van Santen, V. M. H. Sachtler, J. Catal. 196 (2000) 212223.

[28] B. R. Wood, J. A. Reimer, A. T. Bell, J. Catal. 209 (2002) 151-158.

[29] B. M. Abu- Zeid, W. Schwieger, A. Unger, Appl. Catal. B 84 (2008) 277-288. 
[30] A. Waclaw, K. Nowinska, W. Schwieger, A. Zielinska, Catal. Today 90 (2004) 21 25.

[31] M. Kögel, R. Mönnig, W. Schwieger, A. Tissler, T. Turek, J. Catal. 182 (1999) 470478.

[32] G. I. Panov, K. A. Dubkov, E. V. Starokon, Catal. Today 117 (2006) 148-155.

[33] Z. Fu, D. Yin, Y. Yang, X. Guo, Appl. Catal. A 124 (1995) 59-71.

[34] E. Ananieve, A. Reitzmann, Chem. Eng. Sci. 59 (2004) 5509-5517.

[35] K. S.W. Sing, D. H. Everett, R. A.W. Haul, L. Moscou, R.A. Pierotti, J. Rouquerol, T. Siemieniewska, Pure Appl. Chem. 57 (1985) 603-619.

[36] J. H. Park, J. Choung, I. S. Nam, S.W. Ham, Appl. Catal. B 78 (2008) 342-354

[37] G. Berlier, G. Ricchiardi, S. Bordiga, A. Zecchina, J. Catal. 229 (2005) 127-135.

[38] M. S. Kumar, M. Schwidder, W. Grünert, A. Brückner, J. Catal. 227 (2004) 384-397.

[39] S. Bordiga, R. Buzzoni, F. Geobaldo, C. Lamberti, E. Giamello, A. Zecchina, G. G. Leofanti, G. Petrini, G. Tozzola, G. Vlaic, J. Catal. 158 (1996) 486-501.

[40] G. Lehmann, Z. Phys. Chem. Neue Folge 72 (1970) 279-297.

[41] Q. Zhu, B. I. Mojet, R. A. J. Janssen, E. J. M. Hensen, J. van Grondella, P. C. M. M. Magusin, R. A. van Santen, Catal. Lett. 81 (2002) 205-212.

[42] G. I. Kapustin, T. R. Brueva, A. L. Klyachko, S. Beran, B. Wichterlova, Appl. Catal. 42 (1988) 2239-246

[43] I. Melian-Cabrera, S. Espinosa, J. C. Groen, B. van der Linden, F. Kapteijn, J.A. Moulijn, J. Catal. 238 (2006) 250-259.

[44] N.Y. Topsøe, K. Pedersen, E. G. Derouane, J. Catal. 70 (1981) 41-52.

[45] K. Krishna, M. Makkee, Catal. Lett. 106 (2006) 183-193.

[46] T. K. Katranas, A. G. Vlessidis, V. A. Tsiatouras, K. S. Triantafyllidis, N. P. Evmiridis, Micropor. Mesopor. Mater. 61 (2003) 189-198. 
[47] K. Sun, H. Xia, E. Hensen, R. van Santen, C. Li, J. Catal. 238 (2006) 186-95.

[48] P. K. Roy, R. Prins, G. D. Pirngruber, Appl. Catal. A 80 (2008) 226-236.

[49] G. D. Pringruber, P. K. Roy, Catal. Today 110 (2005) 199-210.

[50] Q. Zhu, R. M. van Teeffelen, R. A. van Santen, E. J. M. Hensen, J. Catal. 221 (2004) $575-583$.

[51] G. D. Pringruber, P. K. Roy, N. Weiher, J. Phys. Chem. B 108 (2004) 13746-13754.

[52] E. J. M. Hensen, Q. Zhu, R.A. van Santen J. Catal. 220 (2003) 260-264.

[53] E. J. M. Hensen, Q. Zhu, R. A. J. Janssen, P. C. M. M. Magusin, P. J. Kooyman, R. A. van Santen J. Catal. 233 (2005) 123-135.

[54] E. J. M. Hensen, Q. Zhu, R. A.van. Santen, J. Catal., 233 (2005) 136-146.

[55] G. D. Pirngruber, P. K. Roy, R. Prins, J. Catal. 246 (2007) 147-157.

[56] A. Waclaw, K. Nowinska, Stud. Surf. Sci. Catal. 158 (2005) 877-884.

[57] A. Ates, A. Reitzmann, G. Waters, Appl. Catal. B 119- 120 (2012) 329-339.

[58] El-M. El-Malki, R. van Santen, W. Sachtler, J. Phys. Chem. B 103 (1999) 46114622.

[59] J. Perez-Ramirez, G. Mul, F. Kapteijn, J. A. Moulijn, A. R. Overweg, A. Domenech, A. Ribera, I. W. C. E. Arend, J. Catal. 207 (2002) 113-126.

[60] J. Bandiera, Y. B. Taarit, Appl. Catal. A 132 (1995) 157-167.

[61] M. C. Abello, M. F. Gomeza, M. Casella, O. A. Ferretti, M. A. Banares, J. L. G. Fierro, Appl. Catal. A 251 (2003) 435-447.

[62] A. V. Kucherov, V. D. Nissenbaum, T. N. Kucherova, L. M. Kustov, Kinetic. Catal. 43(1) (2002) 99-106.

[63] N. A. S. Amin, D. D. Anggora, J. Nat. Gas. Chem. 11 (2002) 79-86.

[64]L. V. Pirutko, V. S. Chernyavsky, A. K. Uriarte, G. I. Panov, Appl. Catal. A 227 
(2002)143-157.

\section{Figure and Table Captions}

Table 1. XRD crystallinity and chemical composition of Fe-ZSM-5 and $\mathrm{Fe}-\mathrm{SiO}_{2}$ catalysts.

Table 2. Surface characteristics of $\mathrm{Fe}-\mathrm{ZSM}-5$ and $\mathrm{Fe}-\mathrm{SiO}_{2}$ prepared by heating at $300{ }^{\circ} \mathrm{C}$ under a reduced pressure of $10^{-5}$ Torr.

Table 3. Percentage weight loss of $\mathrm{NH}_{4}-\mathrm{ZSM}-5$ and Fe-ZSM-5 coked in ODHP with $\mathrm{N}_{2} \mathrm{O}$ and/or $\mathrm{O}_{2}$ with increasing temperature between room temperature and $500{ }^{\circ} \mathrm{C}$ or $900{ }^{\circ} \mathrm{C}$ with ramp rate of $10{ }^{\circ} \mathrm{C} / \mathrm{min}$.

Table 4. Initial ODHP results over Fe-ZSM-5 and $\mathrm{Fe}-\mathrm{SiO}_{2}$ using $\mathrm{N}_{2} \mathrm{O}, \mathrm{O}_{2}$ and $\mathrm{N}_{2} \mathrm{O} / \mathrm{O}_{2}$ mixture after LT treatment

Figure 1. DR-UV-vis spectra of Fe-ZSM-5 zeolites treated at LT, HT and ST and Fe-SiO 2 treated at LT. Parent zeolite and silica were used as references.

Figure 2. $\mathrm{NH}_{3}$-TPD of $\mathrm{NH}_{4} \mathrm{ZSM}-5$ zeolites after LT and HT treatment (15 (v/v) \% $\mathrm{NH}_{3}$ in He; $\mathrm{m}_{\text {cat }}=0.2 \mathrm{~g} ; \mathrm{F}_{\text {total }}=25 \mathrm{~cm}^{3} \mathrm{~min}^{-1}$ ).

Figure 3. $\mathrm{NH}_{3}$-TPD of parent zeolites and their iron exchanged forms (15 (v/v) \% $\mathrm{NH}_{3}$ in $\mathrm{He}$; $\left.\mathrm{m}_{\text {cat }}=0.2 \mathrm{~g} ; \mathrm{F}_{\text {total }}=25 \mathrm{~cm}^{3} \min ^{-1}\right)$.

Figure 4. $\mathrm{NH}_{3}$-TPD of Fe-ZSM-5 zeolites treated at LT, HT and ST (15 (v/v) \% $\mathrm{NH}_{3}$ in He; $\left.\mathrm{m}_{\mathrm{cat}}=0.2 \mathrm{~g} ; \mathrm{F}_{\text {total }}=25 \mathrm{~cm}^{3} \mathrm{~min}^{-1}\right)$.

Figure 5. $\mathrm{NH}_{3}-\mathrm{TPD}$ of $\mathrm{SiO}_{2}$ and $\mathrm{Fe}-\mathrm{SiO}_{2}$ samples treated at $500{ }^{\circ} \mathrm{C}$ in $\mathrm{He}\left(15(\mathrm{v} / \mathrm{v}) \% \mathrm{NH}_{3}\right.$ in He; $\mathrm{m}_{\text {cat }}=0.2 \mathrm{~g} ; \mathrm{F}_{\text {total }}=25 \mathrm{~cm}^{3} \mathrm{~min}^{-1}$ ). 
Figure 6. The conversion of propane (a) and nitrous oxide (b), yield (c) and selectivity (d) of propene as a function of time at $450{ }^{\circ} \mathrm{C}$ over Fe-ZSM-5 zeolites at treated at LT (Feed: 5 (v./v.) $\% \mathrm{C}_{3} \mathrm{H}_{8}$ and 5 (v./v.) $\% \mathrm{~N}_{2} \mathrm{O}$ in $\mathrm{He}, \mathrm{m}_{\text {cat }}=0.5 \mathrm{~g} ;$ Ftotal $=200 \mathrm{~cm}^{3} \mathrm{~min}^{-1} ; \mathrm{T}=450{ }^{\circ} \mathrm{C}$ )

Figure 7. The conversion of propane (a) and nitrous oxide (b), yield (c) and selectivity (d) of propene as a function of time at $450{ }^{\circ} \mathrm{C}$ over Fe-ZSM-5 zeolites after consecutive ST and HT (Feed: 5 (v./v.) $\% \mathrm{C}_{3} \mathrm{H}_{8}$ and 5 (v./v.) $\% \mathrm{~N}_{2} \mathrm{O}$ in $\mathrm{He}, \mathrm{m}_{\mathrm{cat}}=0.5$ g; Ftotal $=200 \mathrm{~cm}^{3}$ $\left.\min ^{-1} ; \mathrm{T}=450{ }^{\circ} \mathrm{C}\right)$.

Figure 8. Influence of iron content of silica on ODHP performance (Feed: 5 (v./v.) $\% \mathrm{C}_{3} \mathrm{H}_{8}$ and 5 (v./v.) $\% \mathrm{~N}_{2} \mathrm{O}$ in $\mathrm{He}, \mathrm{m}_{\text {cat }}=0.5 \mathrm{~g} ;$ Ftotal $=200 \mathrm{~cm}^{3} \min ^{-1} ; \mathrm{T}=450{ }^{\circ} \mathrm{C}$ )

Figure 9. Conversion - selectivity plot for the Fe-ZSM-5 catalyst reported in this work and the best results reported in the litterature $[2-5,8,10]$ for Fe-ZSM-5 catalysts. 


\section{Tables}

Table 1. XRD crystallinity and chemical composition of Fe-ZSM-5 and Fe-SiO ${ }_{2}$ catalysts.

\begin{tabular}{|c|c|c|c|c|}
\hline Samples & $\begin{array}{l}\mathrm{Fe} \\
\text { (wt.\%) }\end{array}$ & $\begin{array}{l}\mathrm{Si} / \mathrm{Al} \\
\left(\mathrm{mol} \cdot \mathrm{mol}^{-1}\right)\end{array}$ & $\begin{array}{l}\mathrm{Fe} / \mathrm{Al} \\
\left(\mathrm{mol}^{\mathrm{mol}}{ }^{-1}\right)\end{array}$ & ${ }^{\mathrm{a}}$ Crystal phase \\
\hline SM27Fe1.0 & 1.25 & 12.0 & - & ZSM-5 \\
\hline Z23Fe1.0 & 0.86 & 11.5 & 0.13 & ZSM-5 \\
\hline Z30Fe1.0 & 1.0 & 15.0 & - & ZSM-5 \\
\hline Z50Fe1.0 & 0.93 & 25.0 & 0.34 & ZSM-5 \\
\hline Z80Fe1.0 & 1.0 & 40.0 & - & ZSM-5 \\
\hline $\mathrm{Z} 280 \mathrm{Fe} 1.0$ & 1.33 & 140.0 & 0.04 & ZSM-5 \\
\hline $\mathrm{Fe}-\mathrm{SiO}_{2}-1(\mathrm{~S} 1)$ & 0.1 & $\infty$ & & Silica \\
\hline $\mathrm{Fe}-\mathrm{SiO}_{2}-2(\mathrm{~S} 2)$ & 0.67 & $\infty$ & _ & Silica \\
\hline $\mathrm{Fe}-\mathrm{SiO}_{2}-3(\mathrm{~S} 3)$ & 0.90 & & - & Silica \\
\hline
\end{tabular}

${ }^{\mathrm{a}}$ Determined by XRD 
Table 2. Surface characteristics of Fe-ZSM-5 and $\mathrm{Fe}-\mathrm{SiO}_{2}$ prepared by heating at $300{ }^{\circ} \mathrm{C}$ under a reduced pressure of $10^{-5}$ Torr.

\begin{tabular}{|c|c|c|c|c|c|}
\hline \multirow[t]{2}{*}{ Samples } & \multirow[t]{2}{*}{$\begin{array}{c}\mathrm{S}_{\mathrm{BET}} \\
\left(\mathrm{m}^{2} \mathrm{~g}^{-1}\right)\end{array}$} & \multirow[t]{2}{*}{$\begin{array}{c}\mathrm{S}_{\mathrm{MP}} \\
\left(\mathrm{m}^{2} \mathrm{~g}^{-1}\right)\end{array}$} & \multicolumn{2}{|c|}{$\begin{array}{c}\mathrm{V}_{\mathrm{MP}} \\
\left(\mathrm{cm}^{3} \mathrm{~g}^{-1}\right)\end{array}$} & \multirow[t]{2}{*}{$\begin{array}{l}\mathrm{d}_{\mathrm{MP}} \\
(\AA)\end{array}$} \\
\hline & & & t-plot & DR method & \\
\hline Z23Fe1.0LT & 373 & 300 & 0.10 & 0.14 & 6.9 \\
\hline Z23Fe1.0HT & 346 & 294 & 0.12 & 0.12 & 7.1 \\
\hline Z23Fe1.0ST & 373 & 326 & 0.14 & 0.17 & 9.8 \\
\hline SM27Fe1.0LT & 442 & 254 & 0.08 & 0.16 & 7.1 \\
\hline SM27Fe1.0HT & 334 & 257 & 0.10 & 0.12 & 7.7 \\
\hline SM27Fe1.0ST & 437 & 281 & 0.10 & 0.17 & 8.7 \\
\hline Z30Fe1.0LT & 476 & 394 & 0.16 & 0.19 & 15.6 \\
\hline Z30Fe1.0HT & 396 & 304 & 0.12 & 0.15 & 9.8 \\
\hline Z30Fe1.0ST & 450 & 373 & 0.18 & 0.17 & 11.6 \\
\hline $\mathrm{Z50Fe1.0LT}$ & 419 & 322 & 0.14 & 0.22 & 11.3 \\
\hline Z50Fe1.0HT & 253 & 192 & 0.09 & 0.10 & 12.2 \\
\hline Z50Fe1.0ST & 342 & 276 & 0.14 & 0.14 & 14.4 \\
\hline Z80Fe1.0LT & 464 & 383 & 0.16 & 0.19 & 17.6 \\
\hline Z80Fe1.0HT & 332 & 273 & 0.14 & 0.14 & 14.5 \\
\hline Z80Fe1.0ST & 450 & 373 & 0.18 & 0.17 & 9.4 \\
\hline Z280Fe1.0LT & 417 & - & - & 0.24 & 30.6 \\
\hline Z280Fe1.0HT & 367 & 207 & 0.16 & 0.18 & 10.4 \\
\hline Z280Fe1.0ST & 372 & 325 & 0.16 & 0.14 & 9.4 \\
\hline $\mathrm{Fe}-\mathrm{SiO}_{2}-1$ & 373 & -9 & 0.12 & 0.22 & 27.8 \\
\hline $\mathrm{Fe}-\mathrm{SiO}_{2}-2$ & 290 & n.d & n.d & 0.22 & 31.3 \\
\hline $\mathrm{Fe}-\mathrm{SiO}_{2}-3$ & 360 & n.d & n.d & 0.15 & 31.1 \\
\hline
\end{tabular}

$\mathrm{S}_{\mathrm{BET}}$ : Multi point BET analysis; $\mathrm{S}_{\mathrm{MP}}$ : Micropore area determined by t-plot method; $\mathrm{V}_{\mathrm{MP}}$ :

Micropore volume determined by $\mathrm{t}$-plot and DR methods; $\mathrm{d}_{\mathrm{MP}}$ : Micropore diameter determined by DR method. 
Table 3. Percentage weight loss of $\mathrm{NH}_{4}$-ZSM-5 and Fe-ZSM-5 coked in ODHP with $\mathrm{N}_{2} \mathrm{O}$ and/or $\mathrm{O}_{2}$ with increasing temperature between room temperature and $500{ }^{\circ} \mathrm{C}$ or $900{ }^{\circ} \mathrm{C}$ with ramp rate of $10^{\circ} \mathrm{C} / \mathrm{min}$.

\begin{tabular}{|c|c|c|c|c|c|c|c|c|}
\hline \multirow[t]{2}{*}{ Samples } & \multicolumn{2}{|c|}{ LT } & \multicolumn{2}{|c|}{ HT } & \multicolumn{2}{|c|}{ ST } & \multicolumn{2}{|c|}{ STHT } \\
\hline & $500^{\circ} \mathrm{C}$ & $900{ }^{\circ} \mathrm{C}$ & $500^{\circ} \mathrm{C}$ & $900{ }^{\circ} \mathrm{C}$ & $500^{\circ} \mathrm{C}$ & $900{ }^{\circ} \mathrm{C}$ & $500^{\circ} \mathrm{C}$ & $900{ }^{\circ} \mathrm{C}$ \\
\hline SM27 & 10.7 & 11.6 & & & & & & \\
\hline $\mathrm{Z} 23$ & 10.5 & 11.6 & & & & & & \\
\hline $\mathrm{Z30}$ & 9.2 & 9.9 & & & & & & \\
\hline $\mathrm{Z} 50$ & 7.2 & 8.0 & & & & & & \\
\hline Z80 & 5.8 & 6.6 & & & & & & \\
\hline $\mathrm{Z} 280$ & 2.1 & 2.5 & - & - & - & - & - & - \\
\hline SM27Fe1.0 & 10.4 & 11.8 & - & - & 5.6 & 7.2 & 6.6 & 8.5 \\
\hline Z23Fe1.0 & 7.9 & 10.7 & - & - & & & 6.3 & 7.2 \\
\hline Z30Fe1.0 & 8.2 & 11.0 & - & - & & $\gamma$ & 5.4 & 6.9 \\
\hline Z50Fe1.0 & 9.5 & 13.0 & - & - & & & 7.1 & 8.3 \\
\hline Z80Fe1.0 & 9.0 & 11.2 & 8.2 & 9.6 & 7.5 & 9.0 & 6.0 & 6.6 \\
\hline \multirow[t]{2}{*}{ Z280Fe1.0 } & 6.0 & 6.6 & - & - & 7.9 & 8.6 & 5.9 & 6.7 \\
\hline & & & LT & & HT & & & \\
\hline \multicolumn{3}{|c|}{$\mathrm{Z} 80 \mathrm{Fe} 1.0\left(\mathrm{~N}_{2} \mathrm{O}: \mathrm{C}_{3} \mathrm{H}_{8}=2: 1\right)$} & 9.6 & & 14.2 & & & \\
\hline \multicolumn{3}{|c|}{$\mathrm{Z} 80 \mathrm{Fe} 1.0\left(\mathrm{~N}_{2} \mathrm{O}: \mathrm{C}_{3} \mathrm{H}_{8}: \mathrm{O}_{2}=2: 1: 1\right)$} & 9.0 & & 14.0 & & & \\
\hline \multicolumn{3}{|c|}{$\mathrm{Z} 80 \mathrm{Fe} 1.0\left(\mathrm{C}_{3} \mathrm{H}_{8}: \mathrm{O}_{2}=1: 1\right)$} & 9.0 & & 11.8 & & & \\
\hline \multicolumn{3}{|c|}{$\mathrm{Z} 80 \mathrm{Fe} 1.0\left(\mathrm{O}_{2}: \mathrm{N}_{2} \mathrm{O}: \mathrm{C}_{3} \mathrm{H}_{8}=1: 1: 2\right)$} & 9.7 & & 14.3 & & & \\
\hline
\end{tabular}


Table 4. Initial ODHP results over Fe-ZSM-5 and Fe-SiO $\mathrm{S}_{2}$ using $\mathrm{N}_{2} \mathrm{O}, \mathrm{O}_{2}$ and $\mathrm{N}_{2} \mathrm{O} / \mathrm{O}_{2}$ mixture after LT treatment.

\begin{tabular}{|c|c|c|c|c|c|}
\hline Samples & $\begin{array}{c}\mathrm{C}_{3} \mathrm{H}_{8} / \mathrm{N}_{2} \mathrm{O} / \mathrm{O}_{2} \\
(\% \text { vol. })\end{array}$ & $\begin{array}{c}\mathrm{T} \\
(\mathrm{o} \mathrm{C}) \\
\end{array}$ & $\begin{array}{l}\mathrm{X}_{\mathrm{C} 3 \mathrm{H} 8} \\
(\%) \\
\end{array}$ & $\begin{array}{l}\mathrm{S}_{\mathrm{C} 3 \mathrm{H} 6} \\
(\%)\end{array}$ & $\begin{array}{c}\mathrm{Y}_{\mathrm{C} 3 \mathrm{H} 6} \\
(\%)\end{array}$ \\
\hline SM27Fe 1.0 & $5 / 5 /-$ & 450 & 9.50 & 62.8 & 5.9 \\
\hline $\mathrm{Z} 23 \mathrm{Fe} 086$ & $5 / 5 /-$ & 450 & 39.0 & 17.0 & 6.0 \\
\hline Z30Fe1.0 & $5 / 5 /-$ & 450 & 33.0 & 20.0 & 7.0 \\
\hline $\mathrm{Z} 50 \mathrm{Fe} 0.90$ & $5 / 5 /-$ & 450 & 29.0 & 19.0 & 5.0 \\
\hline Z80Fe1.0 & $5 / 5 /-$ & 450 & 28.0 & 21.0 & 6.0 \\
\hline Z280Fe1.0 & $5 / 5 /-$ & 450 & 25.0 & 39.0 & 9.8 \\
\hline Z280Fe1.0 & $5 / 5 /-$ & 500 & 23.8 & 73.2 & 17.4 \\
\hline $\mathrm{Z} 280 \mathrm{Fe} 1.0$ & $5 /-/ 5$ & 500 & 2.4 & 57.6 & 2.0 \\
\hline Z80Fe1.0 & $5 /-/ 5$ & 500 & 3.0 & 89.2 & 2.6 \\
\hline Z80Fe1.1 & $5 / 2.5 / 2.5$ & 500 & 15.8 & 81.8 & 12.8 \\
\hline Z80Fe1.0 & $5 / 10 /-$ & 500 & 29.2 & 68.8 & 20.0 \\
\hline Z80Fe1.1 & $5 / 10 / 5$ & 500 & 14.9 & 88.9 & 13.2 \\
\hline Z80Fe1.0 & $5 / 5 /-$ & 450 & 14.6 & 75.4 & 11.0 \\
\hline $\mathrm{FeSiO}_{2}-1$ & $5 / 5 /-$ & 450 & 1.1 & 96.6 & 1.0 \\
\hline $\mathrm{FeSiO}_{2}-2$ & $5 / 5 /-$ & 450 & 3.8 & 97.6 & 3.9 \\
\hline $\mathrm{FeSiO}_{2}-2$ & $5 / 5 /-$ & 500 & 3.8 & 98.8 & 5.7 \\
\hline $\mathrm{FeSiO}_{2}-3$ & $5 / 5 /-$ & 450 & 4.6 & 98.6 & 4.6 \\
\hline $\mathrm{FeSiO}_{2}-3$ & $5 /-/ 5$ & 450 & 3.1 & 89.3 & 2.8 \\
\hline $\mathrm{FeSiO}_{2}-3$ & $5 / 10 /-$ & 450 & 4.9 & 97.9 & 4.8 \\
\hline $\mathrm{FeSiO}_{2}-3$ & $5 / 5 / 5$ & 450 & 7.9 & 89.8 & 7.2 \\
\hline
\end{tabular}




\section{FIGURES}

Figure 1.

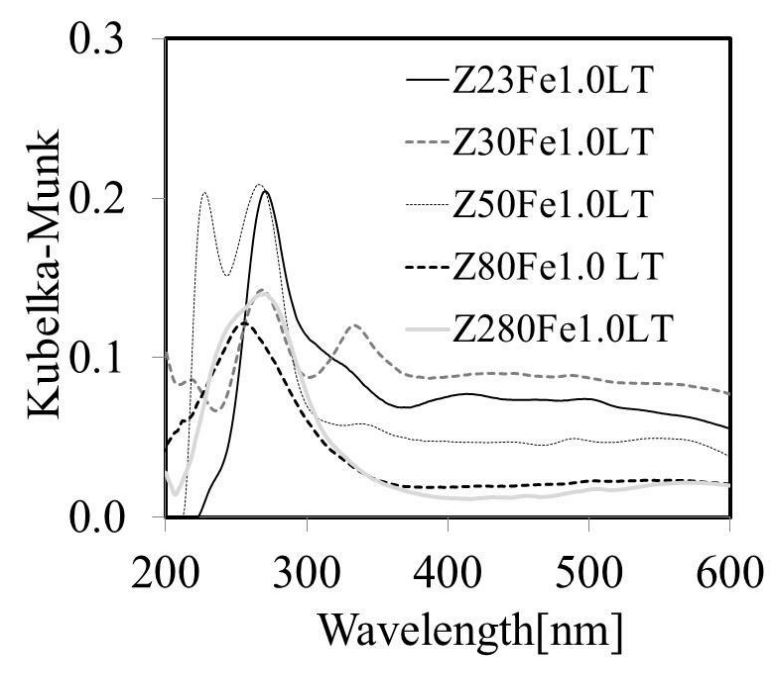

(a)

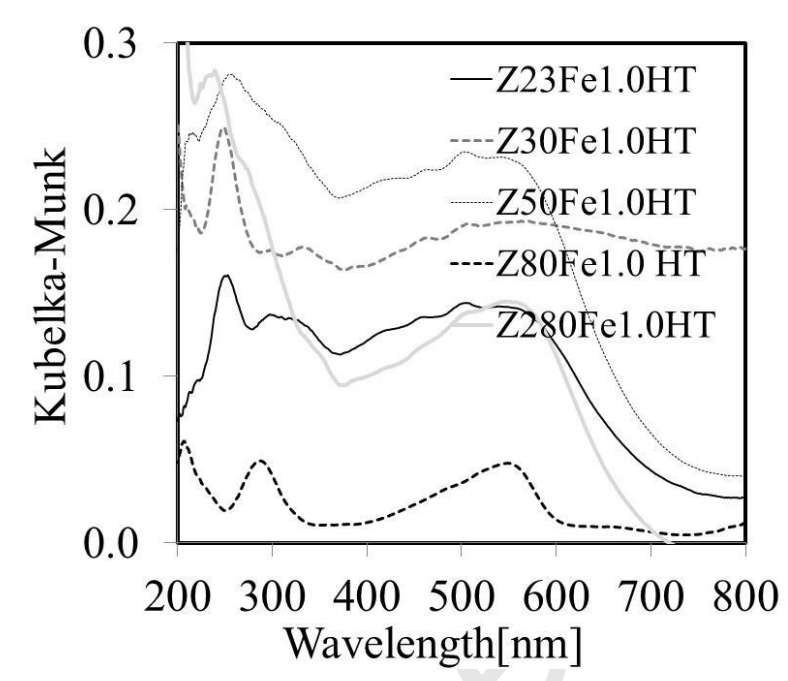

(c)

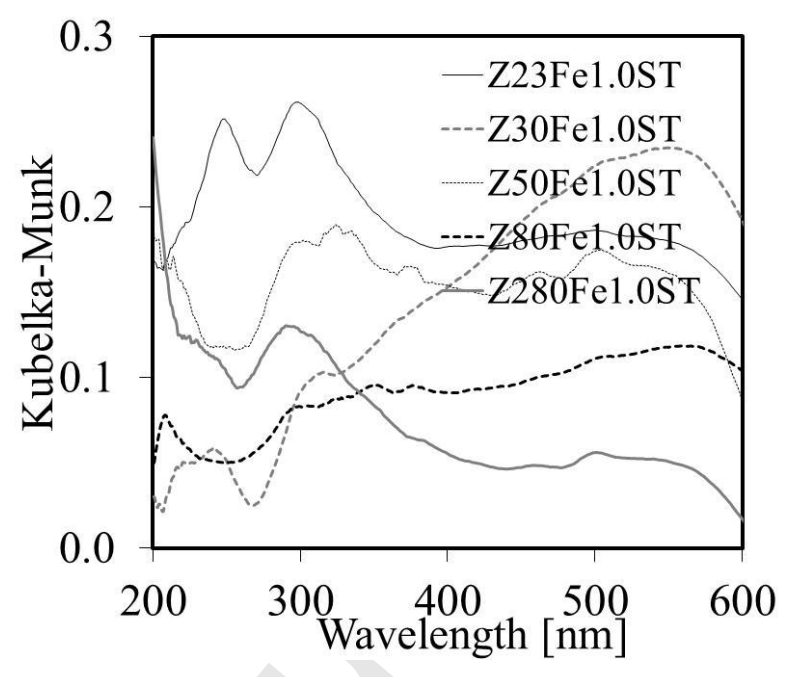

(b)

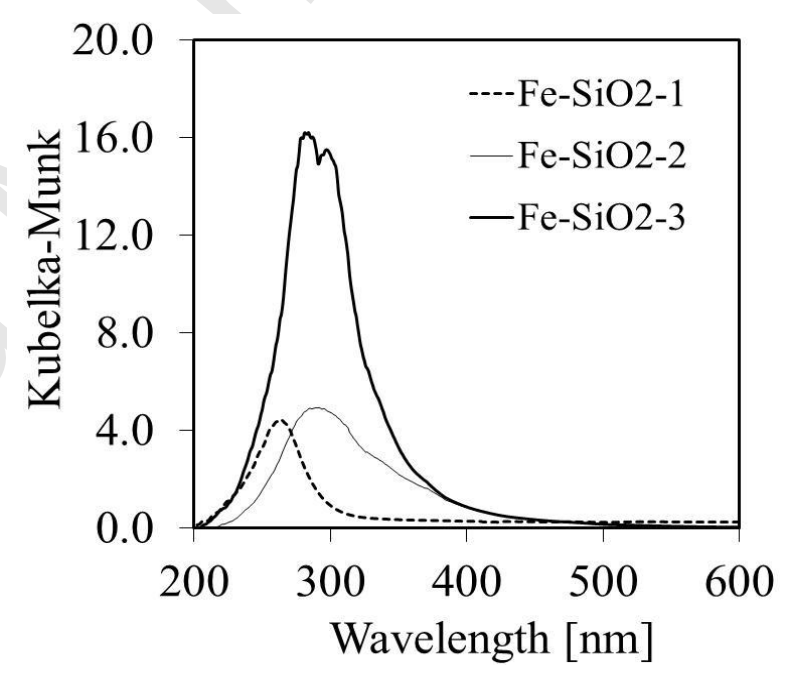

(d) 
Figure 2.
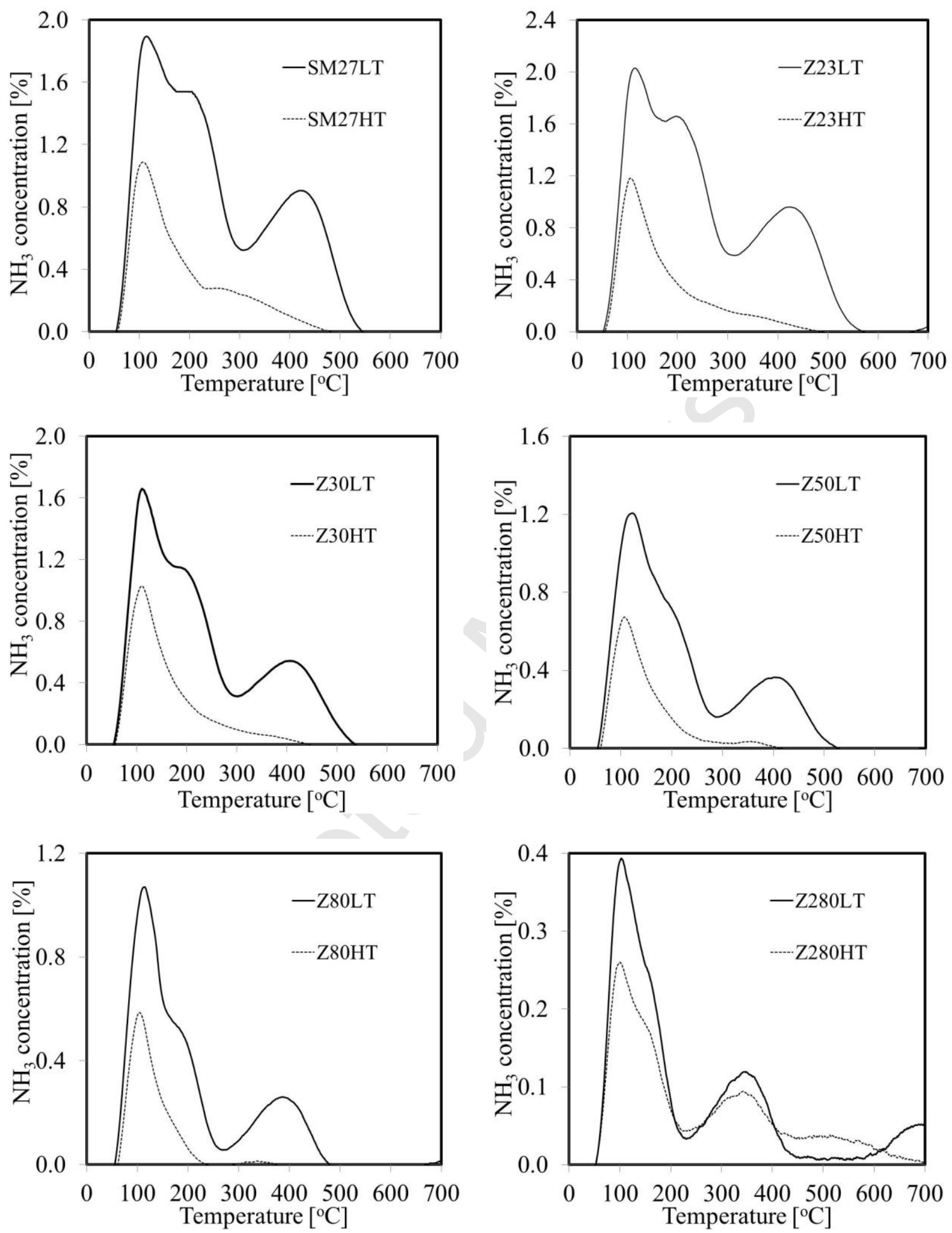
Figure 3.
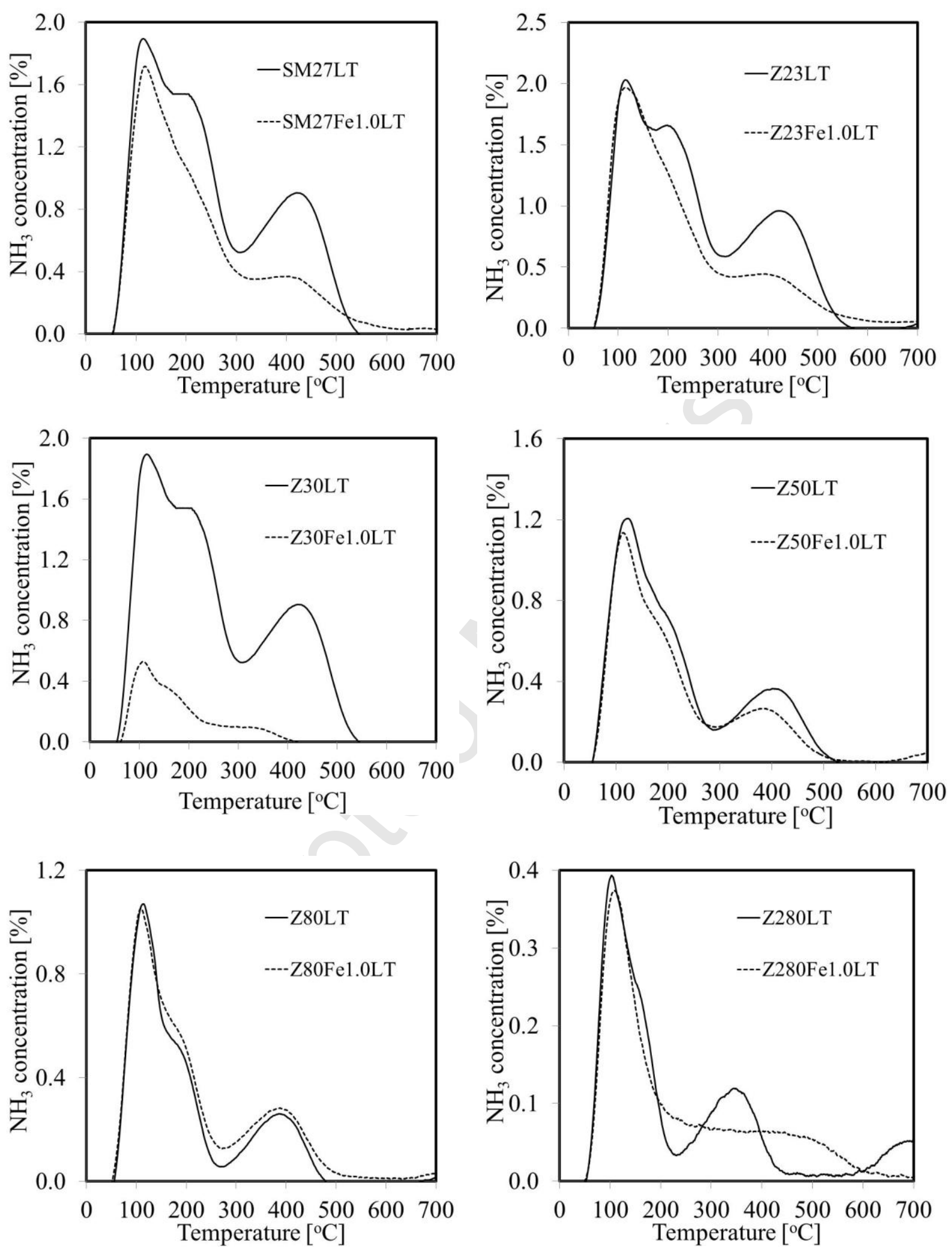
Figure 4.
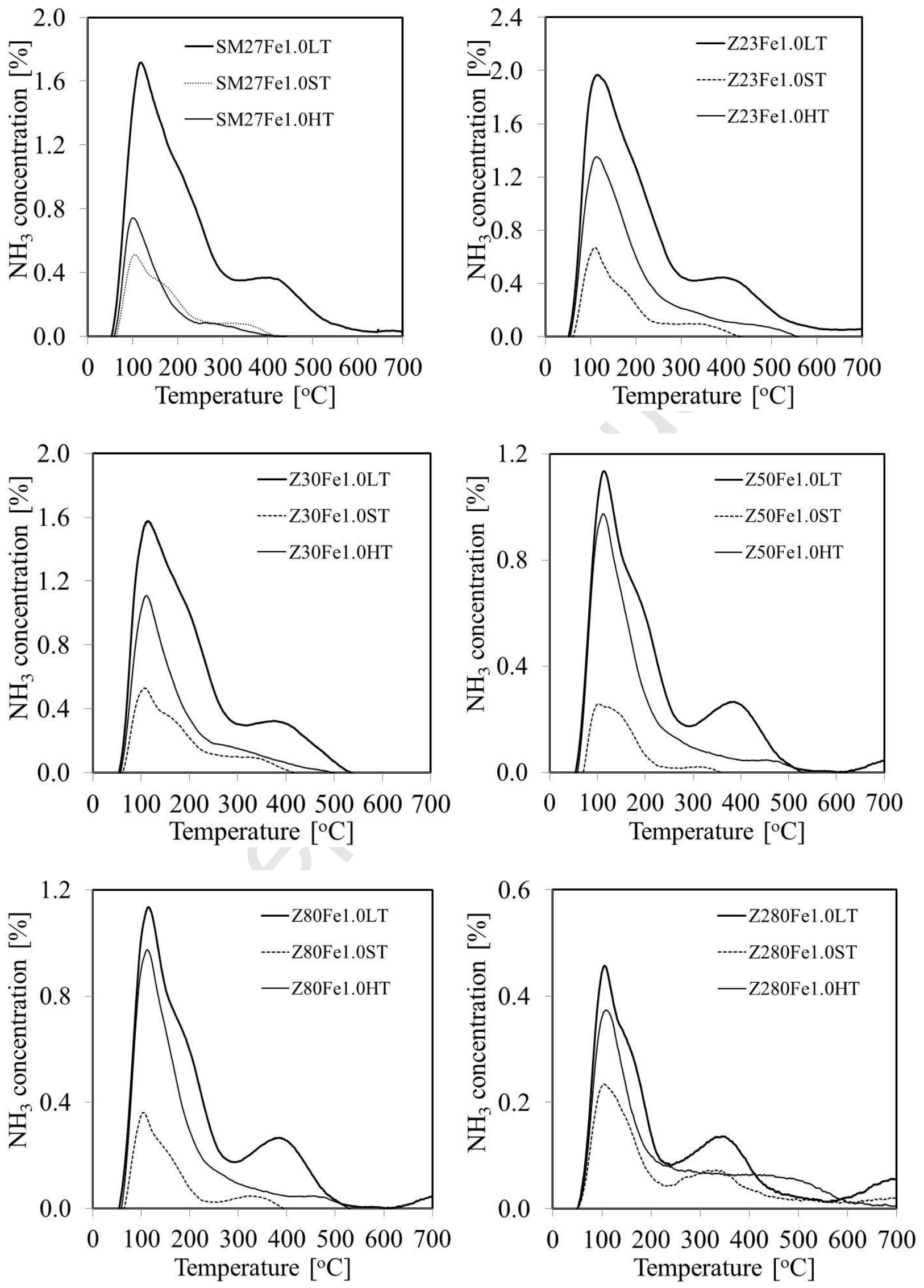
Figure 5.

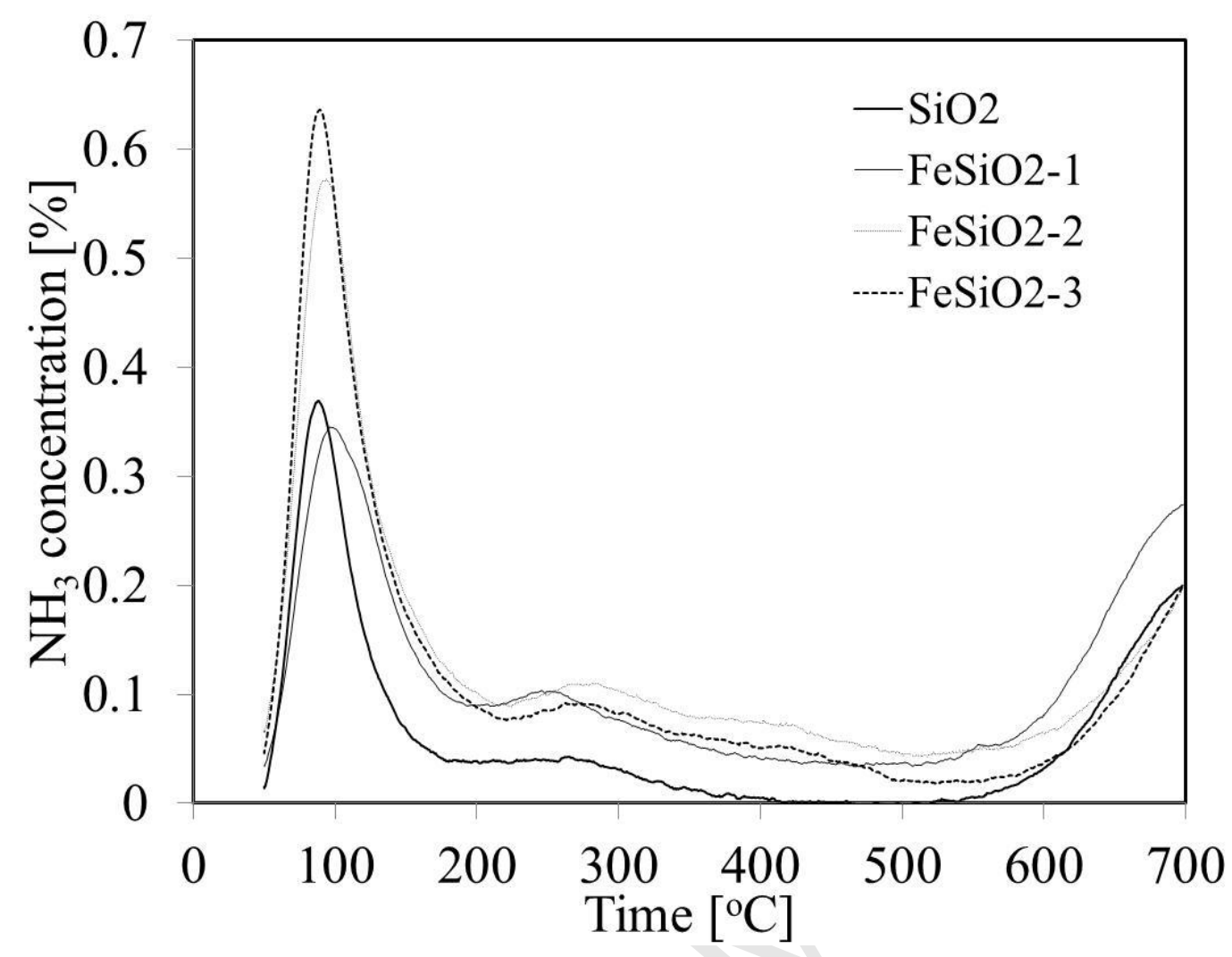


Figure 6.

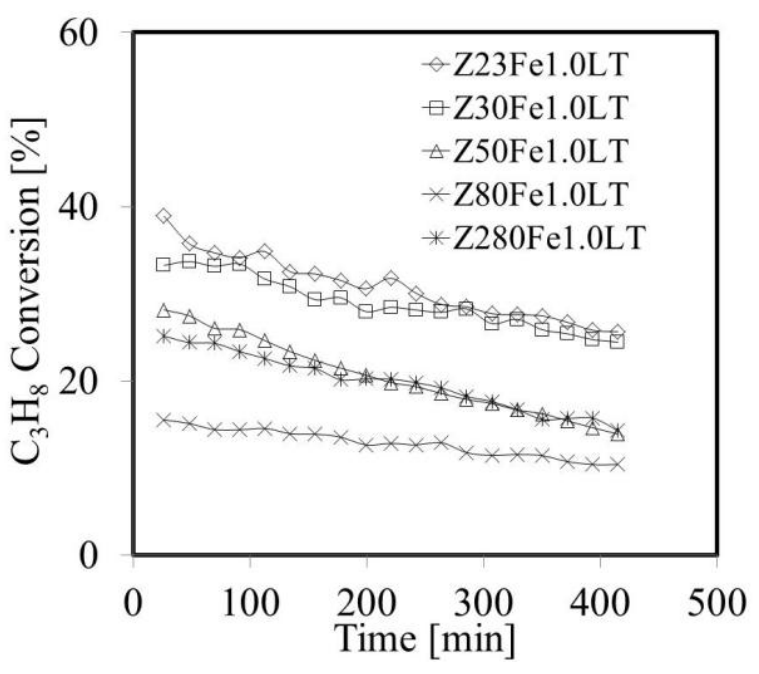

(a)

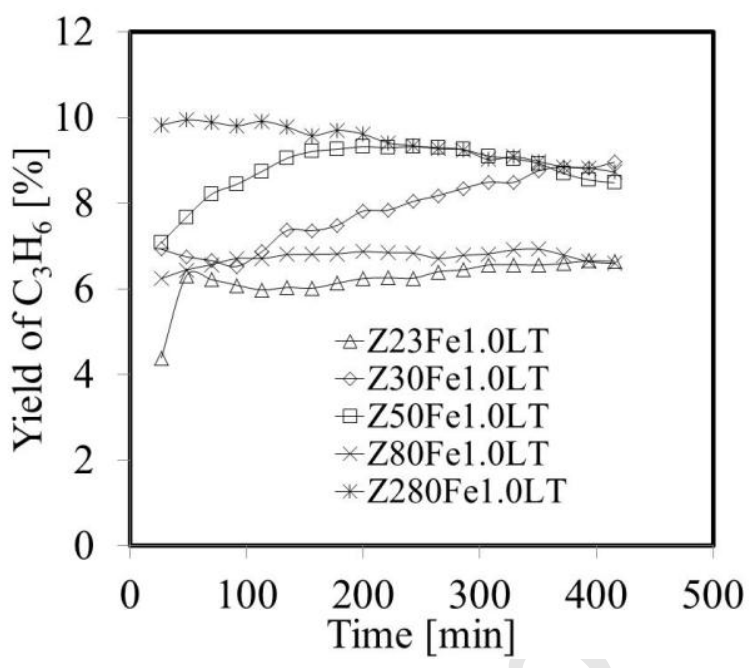

(c)

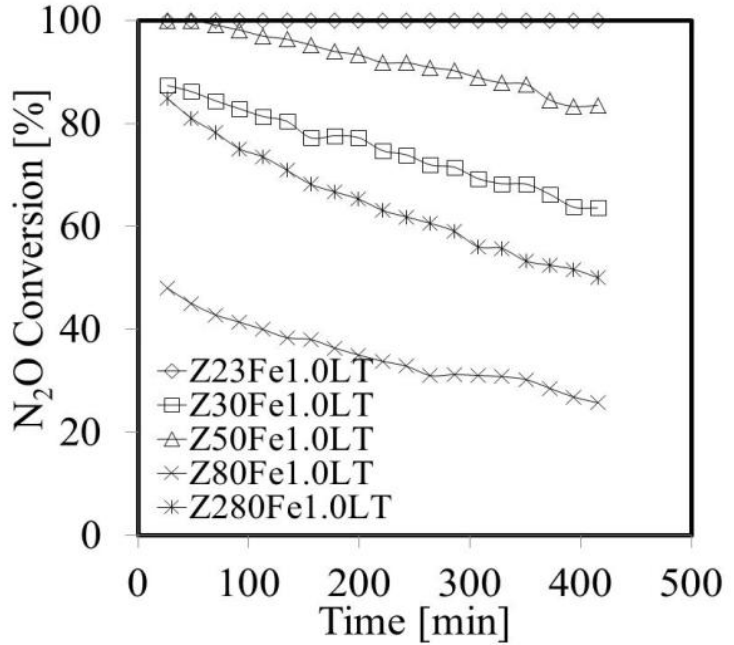

(b)

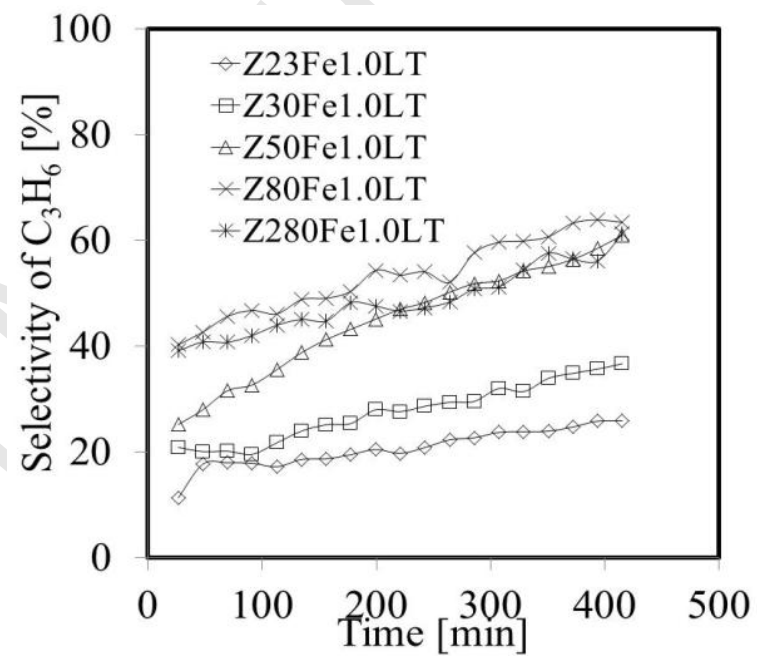

(d) 
Figure 7.

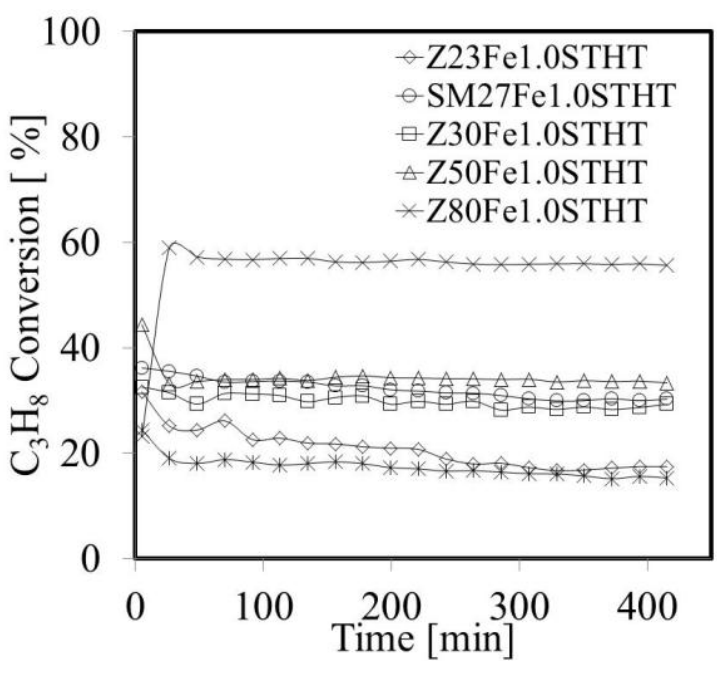

(a)

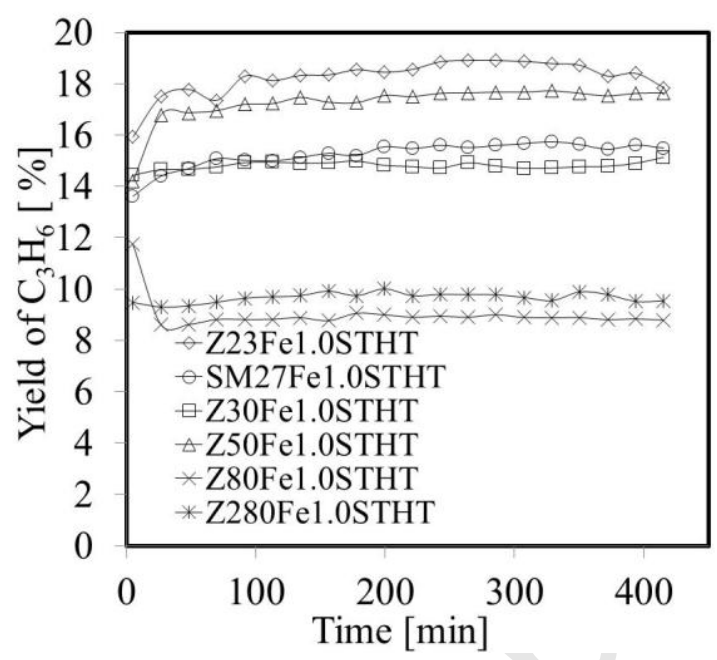

(c)

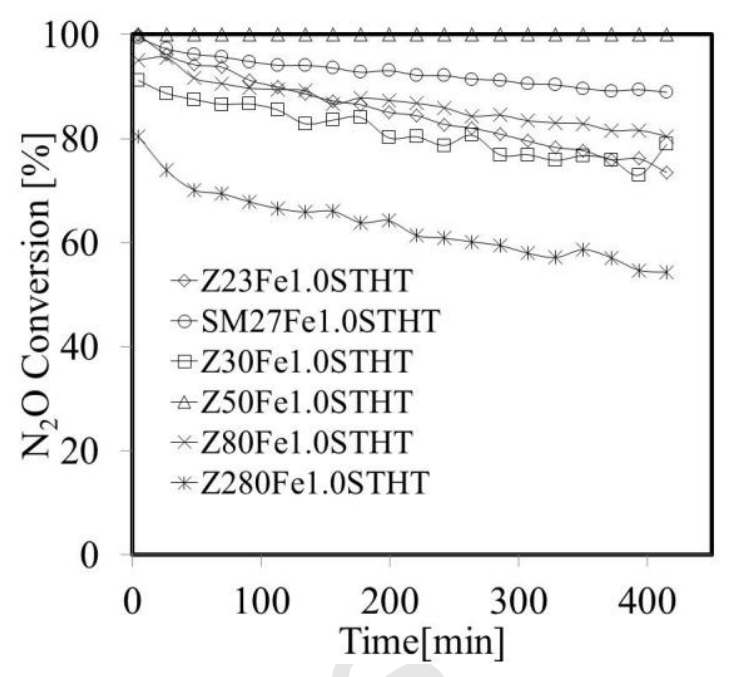

(b)

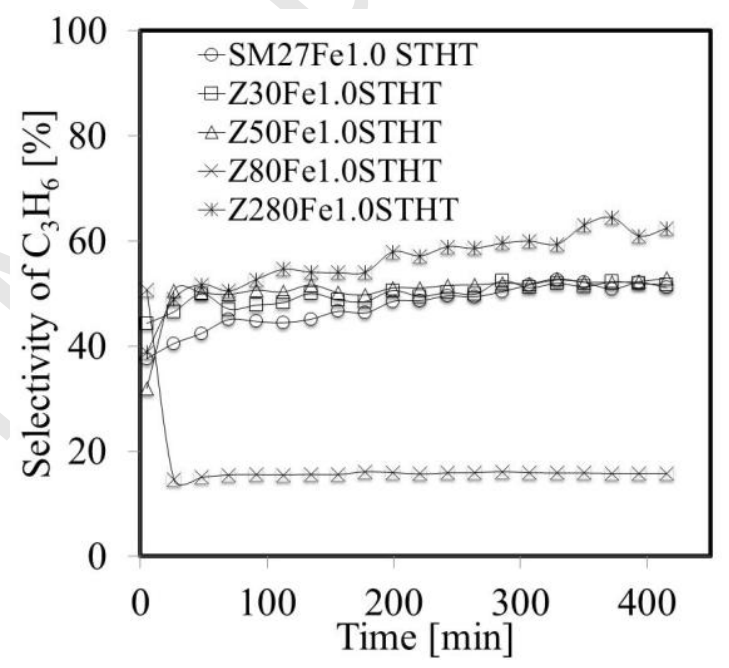

(d) 
Figure 8.

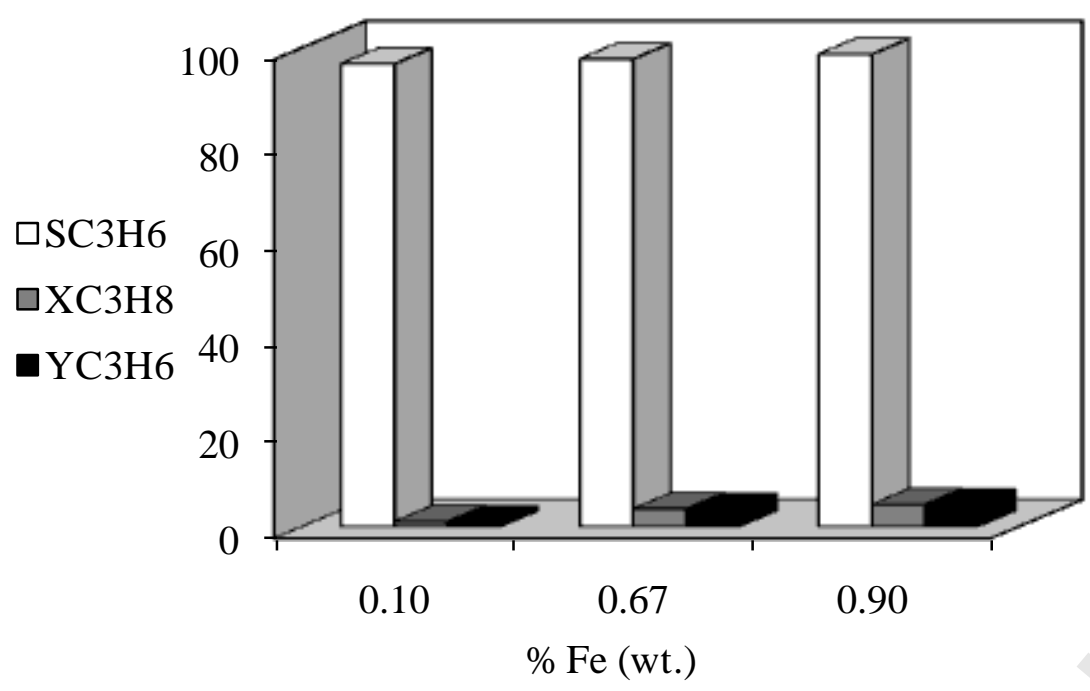


Figure 9.

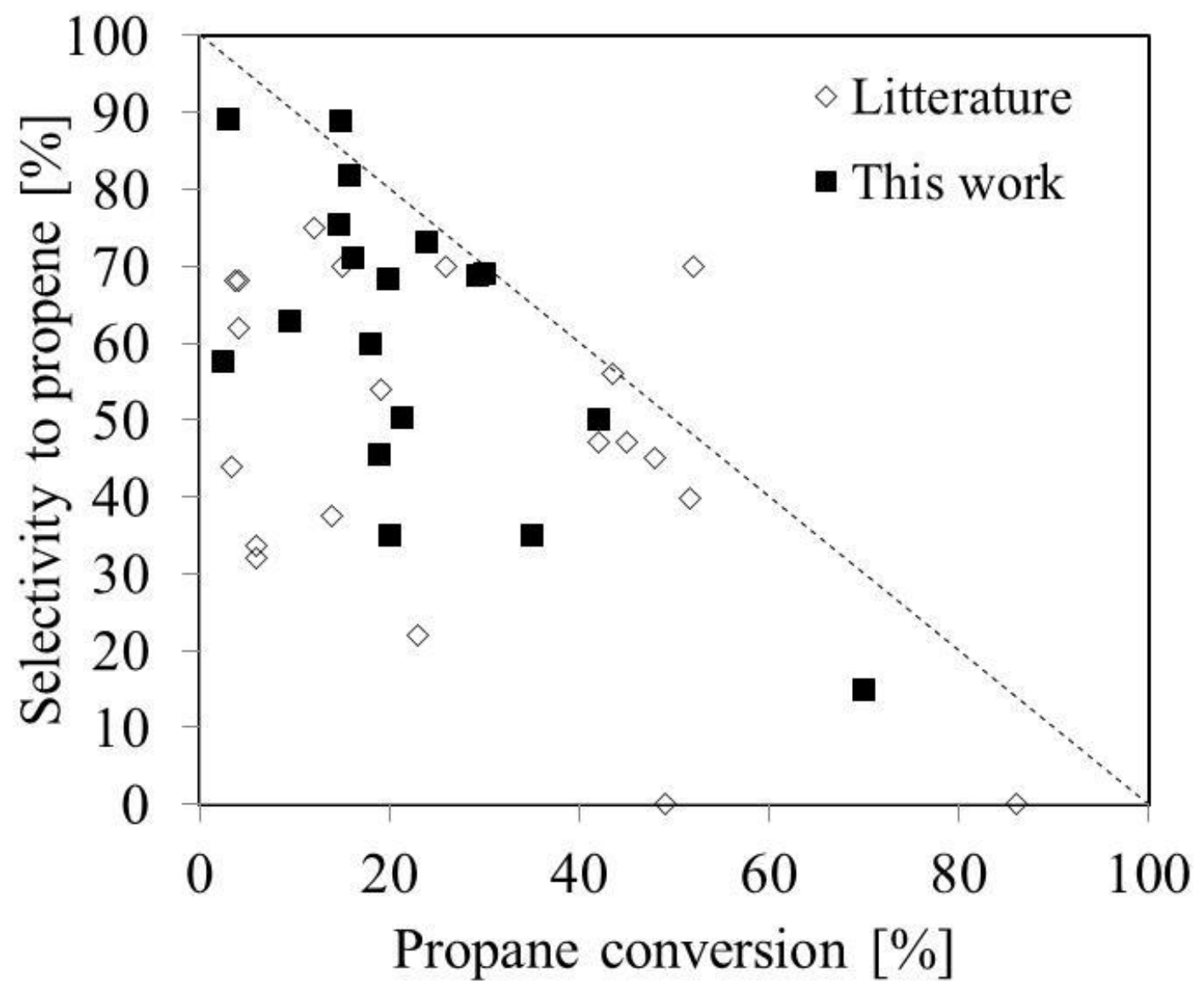

